\title{
Cabbage and fermented vegetables: From death rate heterogeneity in countries to candidates for mitigation strategies of severe COVID-19
}

\author{
Jean Bousquet ${ }^{1,2,3}$ | Josep M. Anto ${ }^{4,5,6,7}$ | Wienczyslawa Czarlewski ${ }^{8,9}$ | Tari Haahtela ${ }^{10}$ (D) \\ Susana C. Fonseca $^{11}$ | Guido laccarino ${ }^{12}$ | Hubert Blain ${ }^{13}$ | Alain Vidal ${ }^{14,15}$ | \\ Aziz Sheikh $^{16}$ | Cezmi A. Akdis ${ }^{17}$ (D) | Torsten Zuberbier ${ }^{1,2}$ (D) | ARIA group \\ ${ }^{1}$ Charité, Universitätsmedizin Berlin, Humboldt-Universität zu Berlin, Berlin, Germany \\ ${ }^{2}$ Department of Dermatology and Allergy, Berlin Institute of Health, Comprehensive Allergy Center, Berlin, Germany \\ ${ }^{3}$ MACVIA-France and CHU, Montpellier, France \\ ${ }^{4}$ Centre for Research in Environmental Epidemiology (CREAL), ISGlobAL, Barcelona, Spain \\ ${ }^{5}$ IMIM (Hospital del Mar Research Institute), Barcelona, Spain \\ ${ }^{6}$ Universitat Pompeu Fabra (UPF), Barcelona, Spain \\ ${ }^{7}$ CIBER Epidemiología y Salud Pública (CIBERESP), Barcelona, Spain \\ ${ }^{8}$ MASK-Air, Montpellier, France \\ ${ }^{9}$ Medical Consulting Czarlewski, Levallois, France \\ ${ }^{10}$ Skin and Allergy Hospital, Helsinki University Hospital, University of Helsinki, Finland \\ ${ }^{11}$ Faculty of Sciences, GreenUPorto - Sustainable Agrifood Production Research Centre, DGAOT, University of Porto, Porto, Portugal \\ ${ }^{12}$ Department of Advanced Biomedical Sciences, Federico II University, Napoli, Italy \\ ${ }^{13}$ Department of Geriatrics, Montpellier University hospital and MUSE, Montpellier, France \\ ${ }^{14}$ World Business Council for Sustainable Development (WBCSD), Geneva, Switzerland \\ ${ }^{15}$ AgroParisTech - Paris Institute of Technology for Life, Food and Environmental Sciences, Paris, France \\ ${ }^{16}$ Usher Institute, University of Edinburgh, Scotland, UK \\ ${ }^{17}$ Swiss Institute of Allergy and Asthma Research (SIAF), University of Zurich, Davos, Switzerland
}

\section{Correspondence}

Jean Bousquet, MACVIA-France and CHU, 273 avenue d'Occitanie, 34090 Montpellier, France.

Email: jean.bousquet@orange.fr

\begin{abstract}
Large differences in COVID-19 death rates exist between countries and between regions of the same country. Some very low death rate countries such as Eastern Asia, Central Europe, or the Balkans have a common feature of eating large quantities of fermented foods. Although biases exist when examining ecological studies, fermented vegetables or cabbage have been associated with low death rates in European countries. SARS-CoV-2 binds to its receptor, the angiotensin-converting enzyme 2 (ACE2). As a result of SARS-CoV-2 binding, ACE2 downregulation enhances the angiotensin II receptor type $1\left(A_{1} R\right)$ axis associated with oxidative stress. This leads to insulin resistance as well as lung and endothelial damage, two severe outcomes of
\end{abstract}

Abbreviations: ACE, angiotensin-converting enzyme; Ang II, angiotensin II; AT ${ }_{1} \mathrm{R}$, angiotensin II receptor type 1; COVID-19, coronavirus disease 19; GI, gastrointestinal; LAB, lactic acid bacilli; NF-кB, nuclear factor kappa B; Nrf2, nuclear factor (erythroid-derived 2)-like 2; PEDV, porcine epidemic diarrhea virus; ROS, reactive oxygen species; SARS, severe acute respiratory syndrome; SARS-CoV-2, severe acute respiratory syndrome coronavirus 2; TGEV, transmissible gastroenteritis coronavirus infection.

See the ARIA group in Appendix 1.

(c) $2020 \mathrm{EAACl}$ and John Wiley and Sons A/S. Published by John Wiley and Sons Ltd. 
COVID-19. The nuclear factor (erythroid-derived 2)-like 2 (Nrf2) is the most potent antioxidant in humans and can block in particular the $A T_{1} R$ axis. Cabbage contains precursors of sulforaphane, the most active natural activator of Nrf2. Fermented vegetables contain many lactobacilli, which are also potent Nrf2 activators. Three examples are: kimchi in Korea, westernized foods, and the slum paradox. It is proposed that fermented cabbage is a proof-of-concept of dietary manipulations that may enhance Nrf2-associated antioxidant effects, helpful in mitigating COVID-19 severity.

\section{KEYWORDS}

angiotensin-converting enzyme 2, cabbage, COVID-19, diet, fermented vegetable, kimchi, Lactobacillus, sulforaphane

\section{1 | INTRODUCTION}

A COVID-19 epidemic started in China and then disseminated to other Asian countries before becoming a pandemic. There is a large variability across countries in both incidence and mortality, and most of the current debates on COVID-19 focus on the differences between countries. Several intertwined factors can be proposed: social distancing, health system capacity, age of the population, social lifestyle (gathering of family/friends, social behavior), testing capacity, and/or timing and intensity of the first outbreak. German fatalities are strikingly low as compared to many European countries. Among the several explanations proposed, an early and large testing of the population was put forward $^{1}$ as well as social distancing. However, little attention has been given to regional within-country differences that may propose new hypotheses.

It would appear that the pandemic has so far resulted in proportionately fewer deaths in some central European countries, the Balkans, China, in most Eastern Asian countries, as well as in many sub-Saharan African countries. Several reasons can explain this picture. One of them may be the type of diet in these low mortality countries. $^{2,3}$

Diet has been proposed to mitigate COVID-19.4,5 Some foods or supplements may have a benefit on the immune response to respiratory viruses. However, to date, there are no specific data available to confirm the putative benefits of diet supplementation, probiotics, and nutraceuticals in the current COVID-19 pandemic. ${ }^{6}$ News and social media platforms have implicated dietary supplements in the treatment and prevention of COVID-19, but without evidence. $^{7}$

In this paper, we discuss country and regional differences in COVID-19 deaths. We attempt to find potential links between foods and differences at the national or regional levels. The aim is to propose a common mechanism focussing on oxidative stress that may be relevant in COVID-19 mitigation strategies. We used cabbage and fermented vegetable as a proof-of-concept.

\section{2 | BIASES TO BE CONSIDERED}

According to the Johns Hopkins Coronavirus Resource Center (https://coronavirus.jhu.edu), one of the most important ways of measuring the burden of COVID-19 is mortality. However, death rates are assessed differently between countries and there are many biases that are almost impossible to assess. Using the rates of COVID-19 confirmed cases is subject to limitations that are similar to or even worse than the differences in the use of COVID-19 testing.

Differences in the mortality rates depend on healthcare systems, the reporting method, and many unknown factors. Countries throughout the world have reported very different case fatality ratios-the number of deaths divided by the number of confirmed cases-but these numbers cannot be compared easily due to biases. On the other hand, for many countries, the methodology used to report death rates in the different regions is standardized across the country.

We used mortality per number of inhabitants to assess death rates, as proposed by the European Center for Disease Prevention and Control (ecdc, https://www.ecdc.europa.eu/en), and to report trends with cutoffs at 25,50,100, and 250 per million.

Our hypothesis is mostly based on ecological data that are hypothesis-generating and that require confirmation by proper studies.

\section{3 | MULTIFACTORIAL ORIGIN OF THE COVID-19 EPIDEMIC}

Like most diseases, COVID-19 exhibits large geographical variations which frequently remain unexplained. ${ }^{8}$ The COVID-19 epidemic is multifactorial, and factors like climate, population density, age, phenotype, and prevalence of noncommunicable diseases are also associated with increased incidence and mortality. ${ }^{9}$ Diet represents only one of the possible causes of the COVID-19 epidemic, and its importance needs to be better assessed. Some risk factors for the COVID-19 epidemics are proposed the individual and country levels in Table 1. 
TAB LE 1 Possible risk factors for COVID-19 infection explaining geographical differences

\begin{tabular}{|c|c|c|c|}
\hline & Measure & Individual level & Country/region level \\
\hline A & $\begin{array}{l}\text { Contact with a SARS-CoV-2 infected } \\
\text { individual }\end{array}$ & ++++ & $\begin{array}{l}\text { Case zero identified } \\
++++ \\
\text { For example, Lombardy }\end{array}$ \\
\hline A & Intensity of social contacts & ++ & +++ \\
\hline A & Intensity of occupational contacts & +++ & ++ \\
\hline A & Confinement (level) & +++ & $\begin{array}{l}\text { For example, the United States versus EU } \\
\text { Sweden vs Nordic countries }\end{array}$ \\
\hline A & Confinement (early measures) & +++ & $\begin{array}{l}+++ \\
\text { For example, the UK versus EU }\end{array}$ \\
\hline A & $\begin{array}{l}\text { Climatic conditions (temperature, } \\
\text { humidity) }\end{array}$ & $?$ & $\begin{array}{l}\text { Hot and humid temperature may reduce infection but epidemic bursts in } \\
\text { Brazil, Peru, and Ecuador }\end{array}$ \\
\hline A & GDP of a country/region & $?$ & + \\
\hline A & Vitamin D & $?$ & + \\
\hline B & Diet & $?$ & $\begin{array}{l}+ \\
\text { The map of COVID-19 deaths in Europe and the low prevalence in Asia } \\
\text { and Africa suggest a role for diet }\end{array}$ \\
\hline B & Food & $++?$ & $\begin{array}{l}\text { Bibliographic analysis suggests a role for some fermented foods. } \\
\text { Raw cabbage can be fermented in the intestine. } \\
\text { Kefir is largely used in many low-prevalence countries. }\end{array}$ \\
\hline B & Long food chain supply & $++?$ & $\begin{array}{l}+ \\
\text { In Italy and Spain, there may be an association with long-chain supply. } \\
\text { This may be relevant since food quality differs. }\end{array}$ \\
\hline B & $\begin{array}{l}\text { Traditional fermented food (example of } \\
\text { food) }\end{array}$ & $++?$ & $\begin{array}{l}++ \\
\text { This may be a relevant issue. In former Eastern European countries, in } \\
\text { the Balkans, in Africa, and in many Asian countries with low COVID-19 } \\
\text { prevalence, traditional fermented foods are common (in line with short } \\
\text { food chain supply) }\end{array}$ \\
\hline B & Air pollution & $+?$ & $+?$ \\
\hline B & Underserved area & ++ & ++ \\
\hline $\begin{array}{l}\text { A } \\
\text { and } \\
\text { C }\end{array}$ & Age & +++ & $\begin{array}{l}+ \text { to }++++ \\
\text { In countries where population is young, fewer people have a severe } \\
\text { disease (e.g., Africa) }\end{array}$ \\
\hline C & Comorbidities (severity of COVID-19) & +++ & ++ \\
\hline C & Sex & ++ & \\
\hline C & Institutionalized person & ++ & \\
\hline
\end{tabular}

Note: A: risk factors at a country level, B: environment, nutrition, C: individual level; + to ++++: Proposed relative importance.

\section{4 | ECOLOGICAL DATA ON COVID-19 DEATH RATES}

When comparing death rates, large differences exist between and within countries, and the evolution of the pandemic differs largely between countries (Figure 1). Although there are many pitfalls in analyzing death rates for COVID-19, ${ }^{3}$ the evolution of death rates between May 20 and July 18 shows a dramatic increase in Latin America and only some increase in European countries, certain African countries, the Middle East, India, Pakistan, and some of the South-East Asian countries. However, there is no change in the very low death rates of Cambodia, China, Japan, Korea, Lao, Malaysia, Taiwan, and Vietnam and of many sub-Saharan African countries, Australia, and New Zealand. This geographical pattern is very unlikely to be totally due to reporting differences between countries.

In some high death rate countries such as Italy (Figure 2), variations are extremely large from 50 per million in Calabria to over 1600 in Lombardia. In Switzerland, the French- and Italian-speaking cantons have a far higher death rate than the German-speaking ones (Office fédéral de la santé publique, Switzerland) (Figure 3). It may be proposed that the high death rate cantons were contaminated by French and Italian people. However, the Mulhouse airport serves the region of Basel (Switzerland), the Haut-Rhin department (France), and the region of Freiburg (Germany). There was a COVID-19 outbreak in the HautRhin department, in particular in Mulhouse and Colmar. The death rate for COVID-19 (May 20, 2020) was 935 per million inhabitants in France but only 10 to 25 in Switzerland and 7 in Germany. It is important to 
May 20
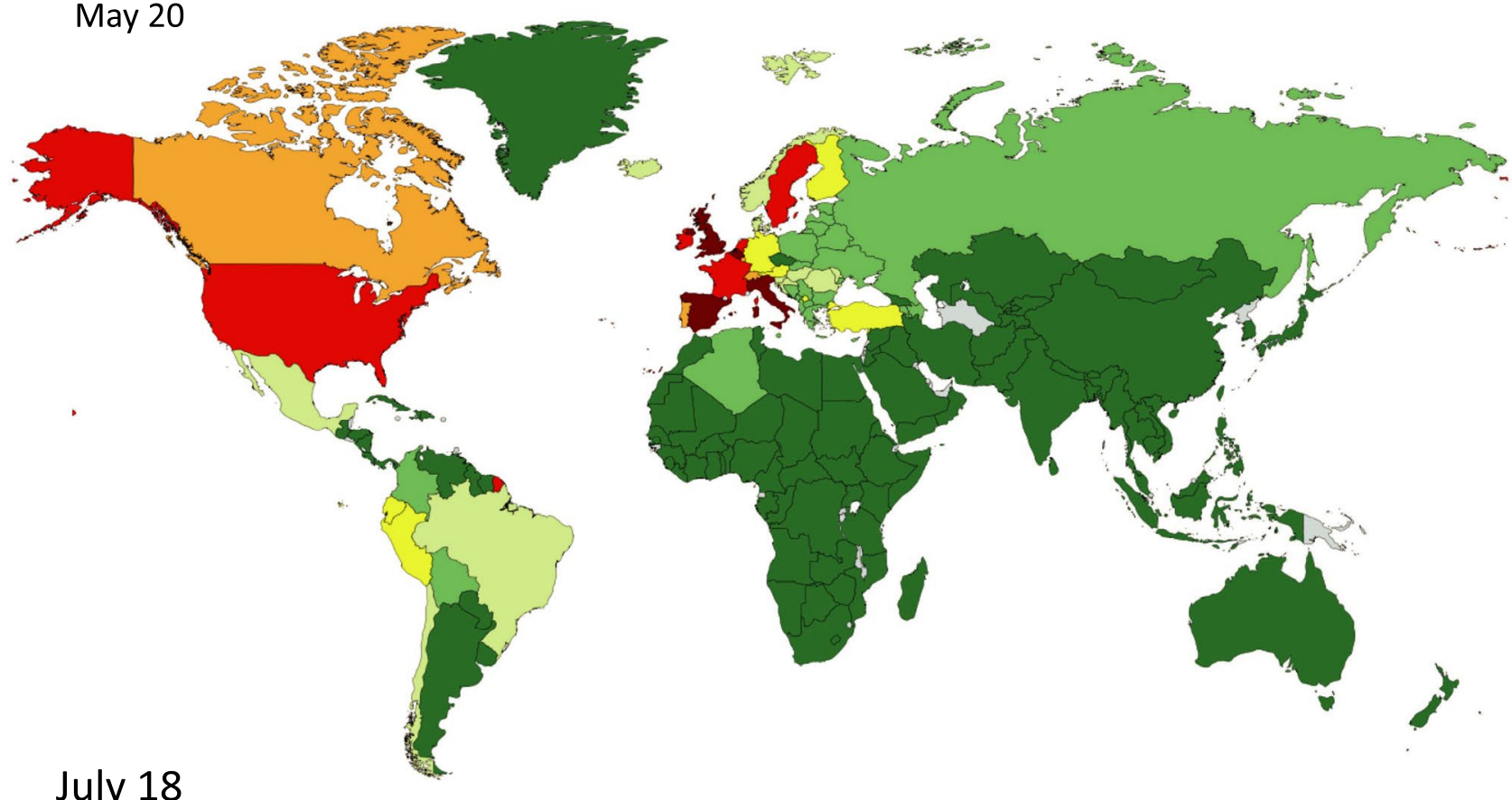

July 18

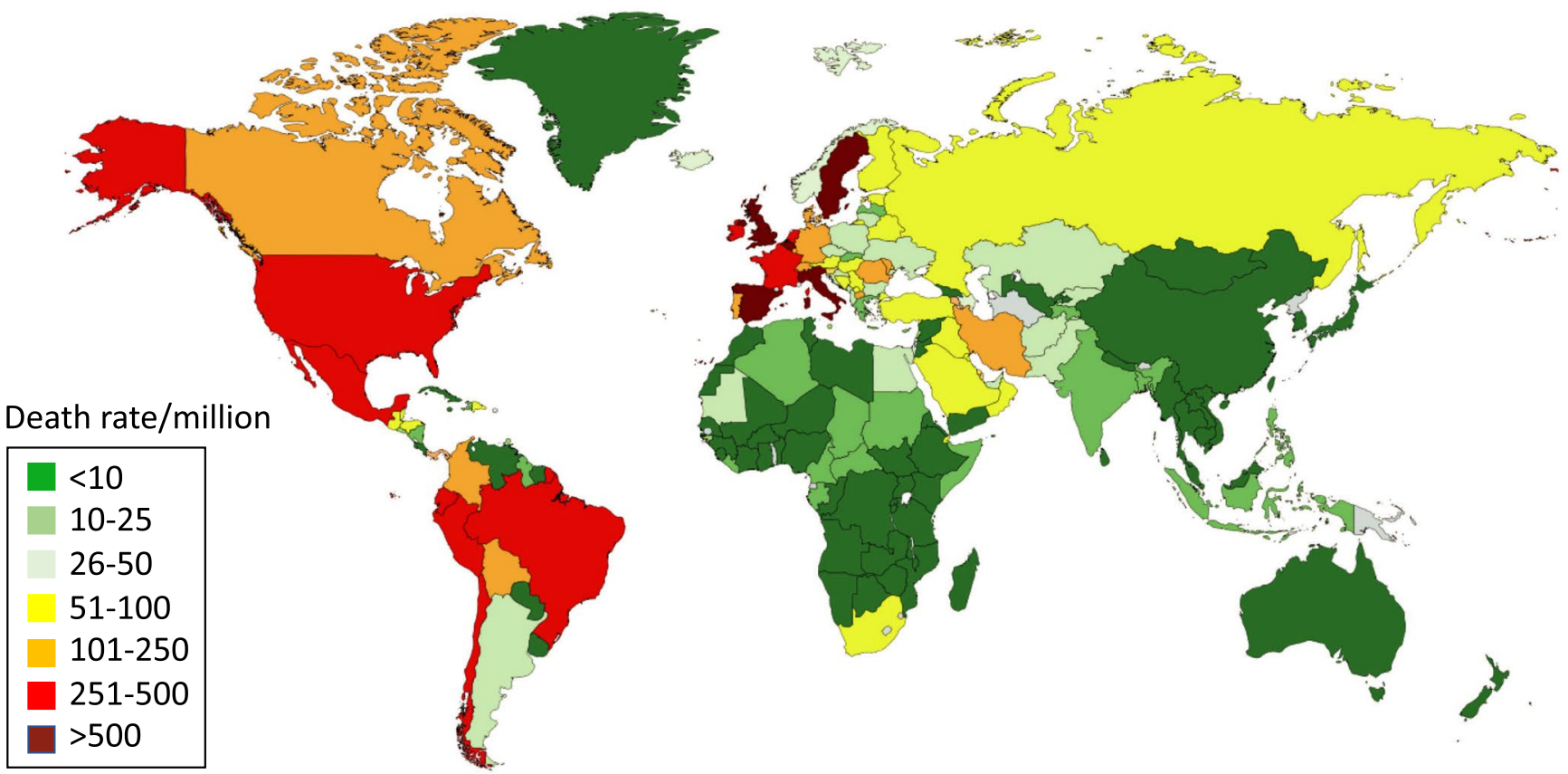

FIGURE 1 COVID-19 deaths per million inhabitants (from Johns Hopkins Coronavirus Center)

consider these regional differences since reporting of deaths is similar within the country and many factors may be considered.

In many Western countries, large cities (eg, London, Madrid, Milan, New York, Paris) have been the most affected. This seems to be true also for many countries in which the rural areas have much fewer cases.

The number of deaths is relatively low in sub-Saharan Africa compared to other regions, and the low population density (which applies in rural areas but not in megacities such as Cairo or Lagos) or the differences in health infrastructure are unlikely to be the only explanation. ${ }^{10}$ It has been proposed that hot temperature may reduce COVID-19, but, in Latin American countries, death rates are high (eg, Brazil, Ecuador, Peru, and Mexico).

\section{5 | IS DIET PARTLY RESPONSIBLE FOR DIFFERENCES BETWEEN AND WITHIN COUNTRIES?}

Nutrition may play a role in the immune defense against COVID-19 and may explain some of the differences seen in COVID-19 between 
FIGURE 2 Regional differences of death rates in Italy (from Worldometer)

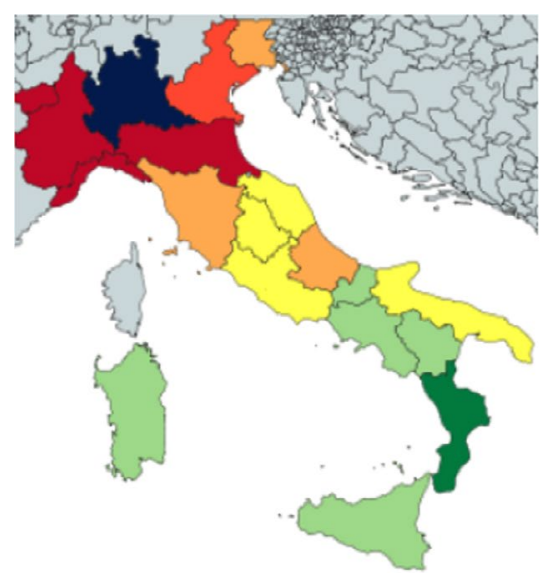

$<50$

50-100

$100-200$

200-400

$400-800$

$800-1600$

$>1600$

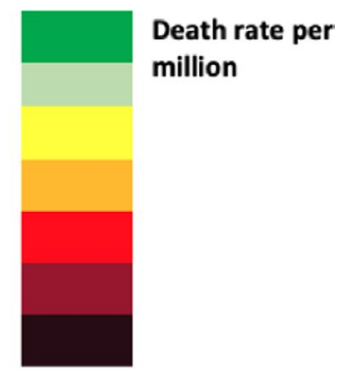

\section{Switzerland}
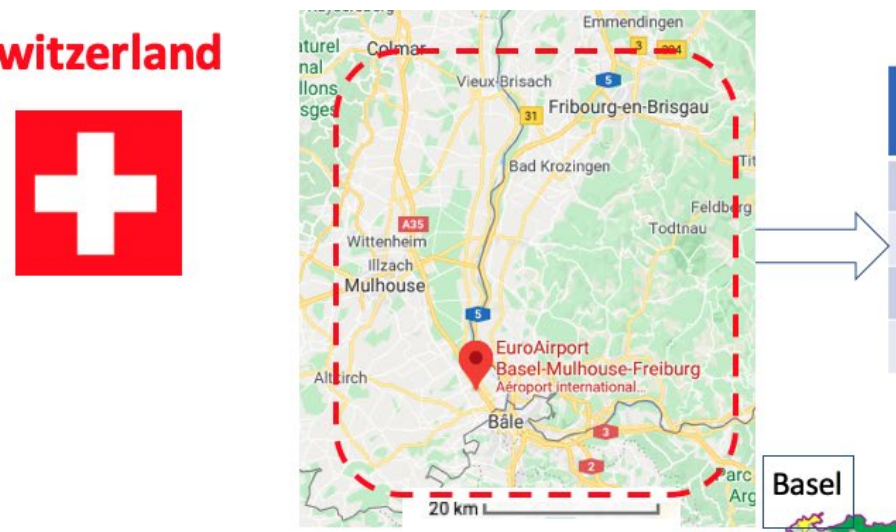

\begin{tabular}{|l|r|r|r|}
\hline May 20, 2020 & Deaths & Population & \multicolumn{2}{|l|}{$\begin{array}{l}\text { Deaths/ } \\
\text { million }\end{array}$} \\
\hline Basel city (Sw) & 49 & 198,000 & 25 \\
\hline Basel-Lands (Sw) & 30 & 298,000 & 10 \\
\hline Freiburg (DE) & 15 & 213,000 & 7 \\
\hline Haut-Rhin (F) & 715 & 765,000 & 935 \\
\hline
\end{tabular}
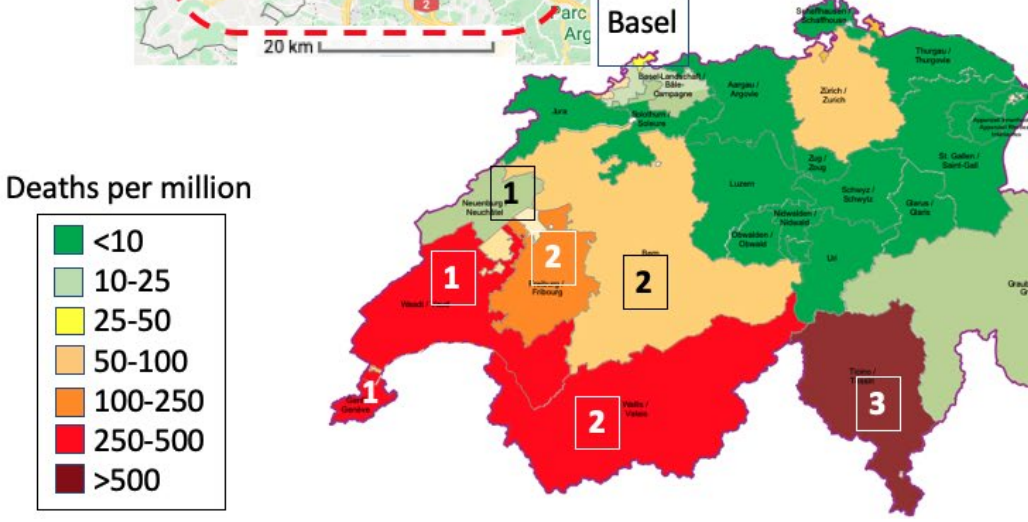

1: French speaking canton 2: Partly French speaking canton 3: Italian speaking canton

FIGURE 3 Regional differences of death rates (May 20) (from Office fédéral de la santé publique, Switzerland, Gouvernement français, Lander Bade Wurtenberg)

and within countries. ${ }^{3}$ In this concept paper, raw and fermented cabbage was proposed as a candidate.

To test the potential role of fermented foods in the COVID-19 mortality in Europe, an ecological study, the European Food Safety Authority (EFSA) Comprehensive European Food Consumption Database, was used to study the country consumption of fermented vegetables, pickled/marinated vegetables, fermented milk, yoghurt, and fermented sour milk. ${ }^{11}$ Of all the variables considered, including confounders, only fermented vegetables reached statistical significance with the COVID-19 death rate per country. For each g/day increase in consumption of fermented vegetables of the country, the mortality risk for COVID-19 was found to decrease by $35.4 \%$ (Figure 4).

A second ecological study has analyzed cruciferous vegetables (broccoli, cauliflower, head cabbage (white, red, and savoy cabbage), leafy brassica) and compared them with spinach, cucumber, courgette, lettuce, and tomato. ${ }^{12}$ Only head cabbage and cucumber reached statistical significance with the COVID-19 death rate per country. For each g/day increase in the average national consumption of some of the vegetables (head cabbage and cucumber), the mortality risk for COVID-19 decreased by a factor of 11 , to $13.6 \%$. The negative ecological association between COVID-19 mortality and consumption of cabbage and cucumber supports the a priori hypothesis previously reported. However, these are ecological studies that need to be further tested.

Another diet component potentially relevant in COVID-19 mortality may be the food supply chain and traditional groceries. ${ }^{13}$ The impact of the long supply chain of food on health is measurable by an increase in metabolic syndrome and insulin resistance. ${ }^{14}$ Therefore, 


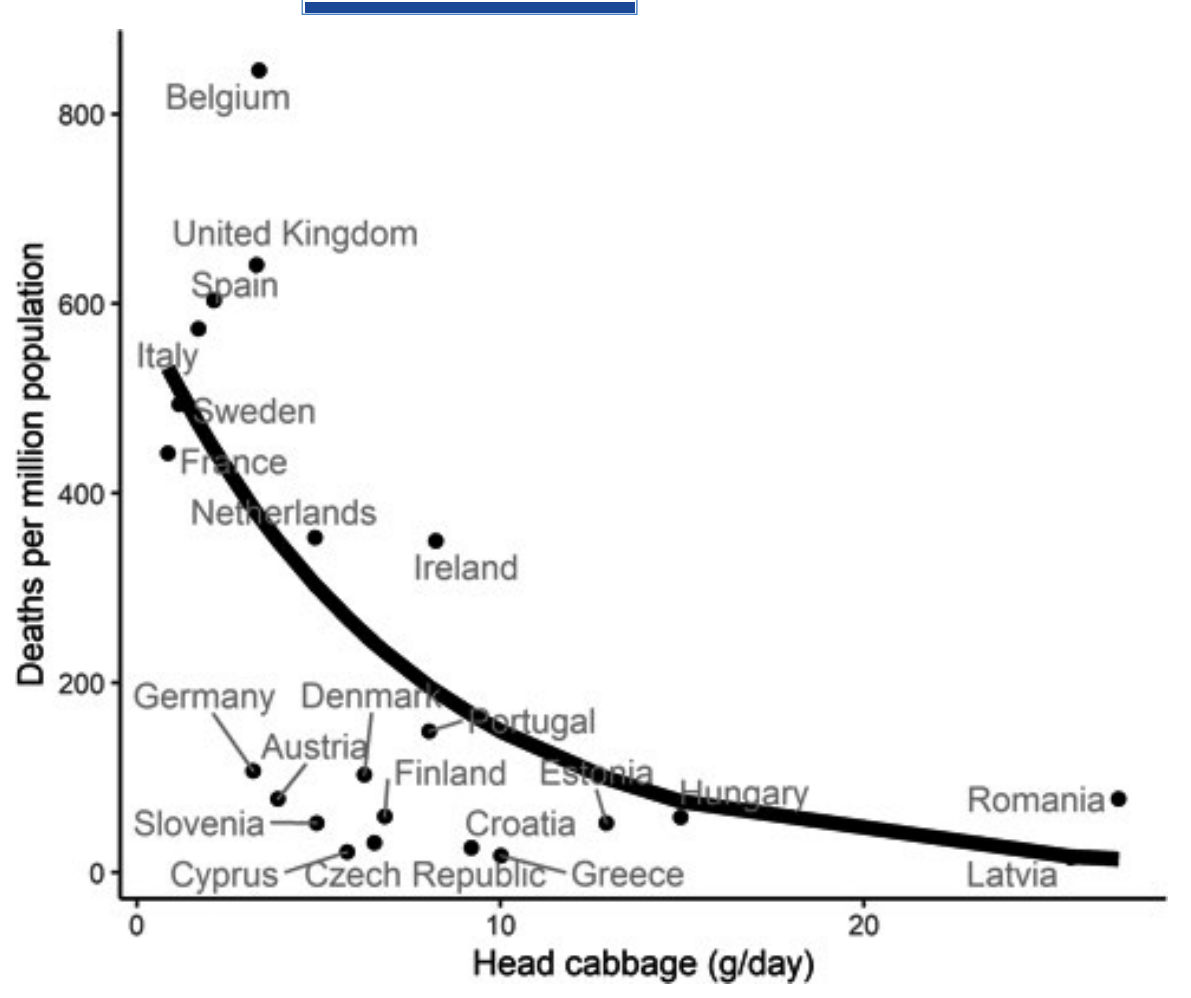

FIGURE 4 Consumption of head cabbage and COVID-19 death rate at a country level (from Fonseca et $\mathrm{al}^{12}$ )

areas that are more prone to short supply food and traditional groceries may have been able to better tolerate COVID-19 with a lower death toll. These considerations may be partly involved in the lower death rates of Southern Italy compared to the northern part (Figure 2).

\section{6 | FERMENTED FOODS, MICROBIOME, AND LACTOBACILLI}

The fermentation process, born as a preservation method in the Neolithic age, enabled humans to eat not-so-fresh food and to survive. ${ }^{15}$ Indigenous fermented foods such as bread, cheese, vegetables, and alcoholic beverages have been prepared and consumed for thousands of years. They are strongly linked to culture and tradition, especially in rural households and village communities, and are consumed by hundreds of millions of people. ${ }^{16}$ Fermented foods are "foods or beverages made via controlled microbial growth (including lactic acid bacteria (LAB)) and enzymatic conversions of food components." 17 Not all fermented foods contain live cultures, as some undergo further processing after fermentation: pasteurization, smoking, baking, or filtration. These processes kill or remove the live microorganisms in foods such as soy sauces, bread, most beers, and wines as well as chocolate. Live cultures can be found in fermented vegetables and fermented milk (fermented sour milk, yoghurt, probiotics, etc.).

Most traditional foods with live bacteria in the low death rate countries are based on LAB fermentation. ${ }^{18} \mathrm{~A}$ number of bacteria are involved in the fermentation of kimchi and other Korean traditional fermented foods, but LAB-including Lactobacillus-are the dominant species in the fermentation process. ${ }^{19,20}$ Lactobacillus is also an essential species in the fermentation of sauerkraut, as well as in Taiwanese, ${ }^{21}$ Chinese, ${ }^{22}$ or other fermented foods. ${ }^{23}$ Lactobacilli are among the most common microorganisms found in kefir, a traditional fermented milk beverage, ${ }^{24}$ milk, and milk products. ${ }^{25,26}$ During fermentation, LAB synthesize vitamins and minerals, and produce biologically active peptides with antioxidant activity. ${ }^{17,27-31}$

Humans possess two protective layers of biodiversity, and the microbiome has been proposed as an important actor of COVID-19. ${ }^{32}$ The environment (outer layer) affects our lifestyle, shaping the microbiome (inner layer). ${ }^{33}$ Many fermented foods contain living microorganisms and modulate the intestinal microbiome. ${ }^{17,31,34-36}$

The composition of microbiomes varies in different regions of the world. ${ }^{37}$ Gut microbiota has an inter-individual variability due to genetic predisposition and diet. ${ }^{38}$ As part of the gut microbiome, Lactobacillus spp. contributes to its diversity and modulates oxidative stress in the GI tract. Some foods like cabbage can be fermented by the gut microbiota. ${ }^{39}$

Westernized foods usually lack fermented vegetables, and milk-derived products have less biodiversity than traditional ones. Urbanization in Western countries was associated with changes in the gut microbiome and with intestinal diversity reduction. ${ }^{38,40-43}$ Westernized food in Japan led to changes in the microbiome and in insulin resistance. ${ }^{44}$ The gut microbiome of westernized urban Saudis had a lower biodiversity than that of the traditional Bedouin population. ${ }^{45}$ Fast food consumption was characterized by reduced Lactobacilli in the microbiome. ${ }^{46}$

The links between gut microbiome, inflammation, obesity, and insulin resistance are being observed, but further large studies are needed for a definite conclusion. ${ }^{47-49}$ 
Some COVID-19 patients have intestinal microbial dysbiosis ${ }^{50}$ with decreased probiotics such as Lactobacillus and Bifidobacterium ${ }^{51}$ Many bacteria are involved in the fermentation of vegetables but most traditional foods with live bacteria in the low death rate countries are based on LAB fermentation. ${ }^{18-20,23,30}$ Lactobacilli are among the most common microorganisms found in milk and milk products. $^{24-26}$

\section{ANGIOTENSIN-CONVERTING ENZYME 2 (ACE2) AND COVID-19}

COVID-19 is more severe in older adults and/or patients with comorbidities such as diabetes, obesity, or hypertension, suggesting a role for insulin resistance. ${ }^{52}$ Although differences exist between countries, the same risk factors for severity were found globally, suggesting common mechanisms. A strong relationship between hyperglycemia, impaired insulin pathway, and cardiovascular disease in type-2 diabetes is linked to oxidative stress and inflammation. ${ }^{53}$ Lipid metabolism has an important role to play in obesity, in diabetes and its multi-morbidities, and in aging. ${ }^{54}$ The increased severity of COVID-19 in diabetic, hypertensive, obese, or elderly individuals may be related to insulin resistance, with oxidative stress as a common pathway. ${ }^{55}$ Moreover, the severe outcomes of COVID-19-including lung damage, cytokine storm, or endothelial damage-appear to exist globally, again suggesting common mechanisms.
The angiotensin-converting enzyme 2 (ACE2) receptor is part of a dual system-the renin-angiotensin-system (RAS)-consisting of an ACE-Angiotensin-II-AT ${ }_{1} \mathrm{R}$ axis and an ACE-2-Angiotensin(1-7)-Mas axis. $A T_{1} R$ is involved in most of the effects of Ang II, including oxidative stress generation, ${ }^{56}$ which in turn upregulates $\mathrm{AT}_{1} \mathrm{R}^{57}$ In metabolic disorders and with older age, there is an upregulation of the $A T_{1} R$ axis leading to pro-inflammatory, pro-fibrotic effects in the respiratory system and to insulin resistance. ${ }^{58}$ SARS-CoV-2 binds to its receptor ACE2 and exploits it for entry into the cell. The ACE2 downregulation, as a result of SARS-CoV-2 binding, enhances the $A T_{1} R$ axis ${ }^{59}$, likely to be associated with insulin resistance ${ }^{60,61}$ but also to severe outcomes of COVID-19 (Figure 5A).

\section{8 | ANTIOXIDANT ACTIVITIES OF FOODS LINKED WITH COVID-19}

Many foods have an antioxidant activity, ${ }^{62-64}$ and the role of nutrition has been proposed to mitigate COVID-19. ${ }^{65}$ Many antioxidant mechanisms have been proposed, and several foods can interact with transcription factors related to antioxidant effects such as the nuclear factor (erythroid-derived 2)-like 2 (Nrf2). ${ }^{4}$ Some processes like fermentation increase the antioxidant activity of milk, cereals, fruit, vegetables, meat, and fish. ${ }^{29}$
(A)

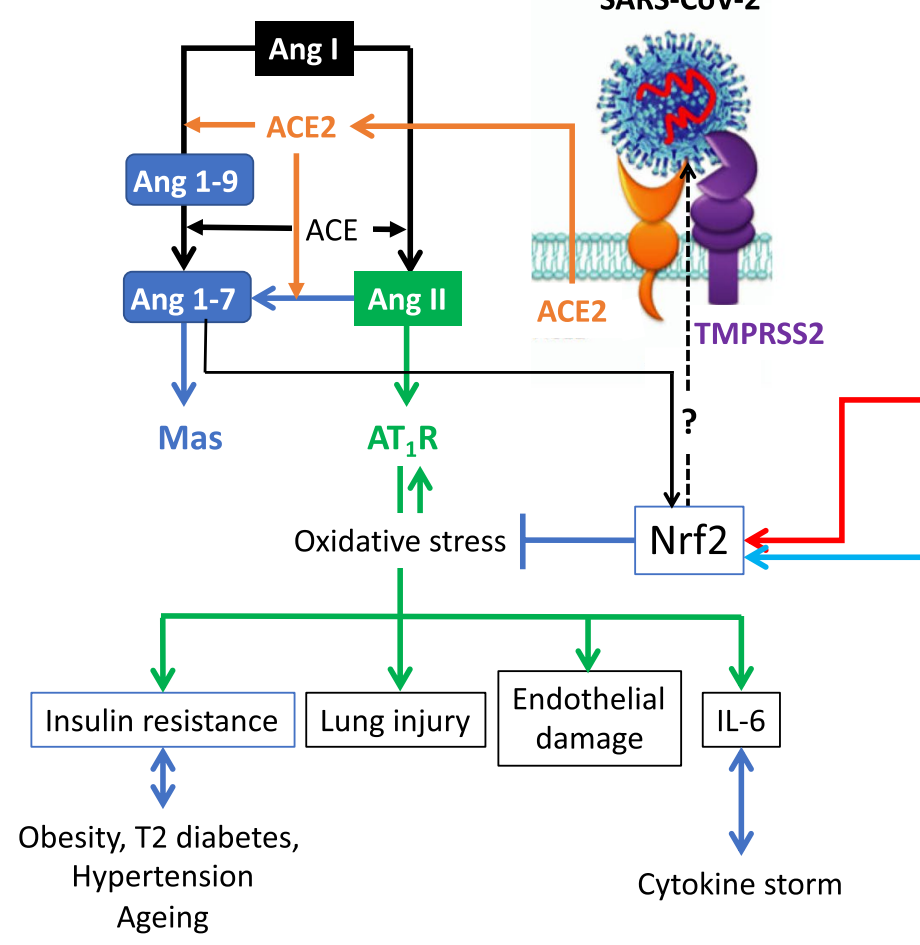

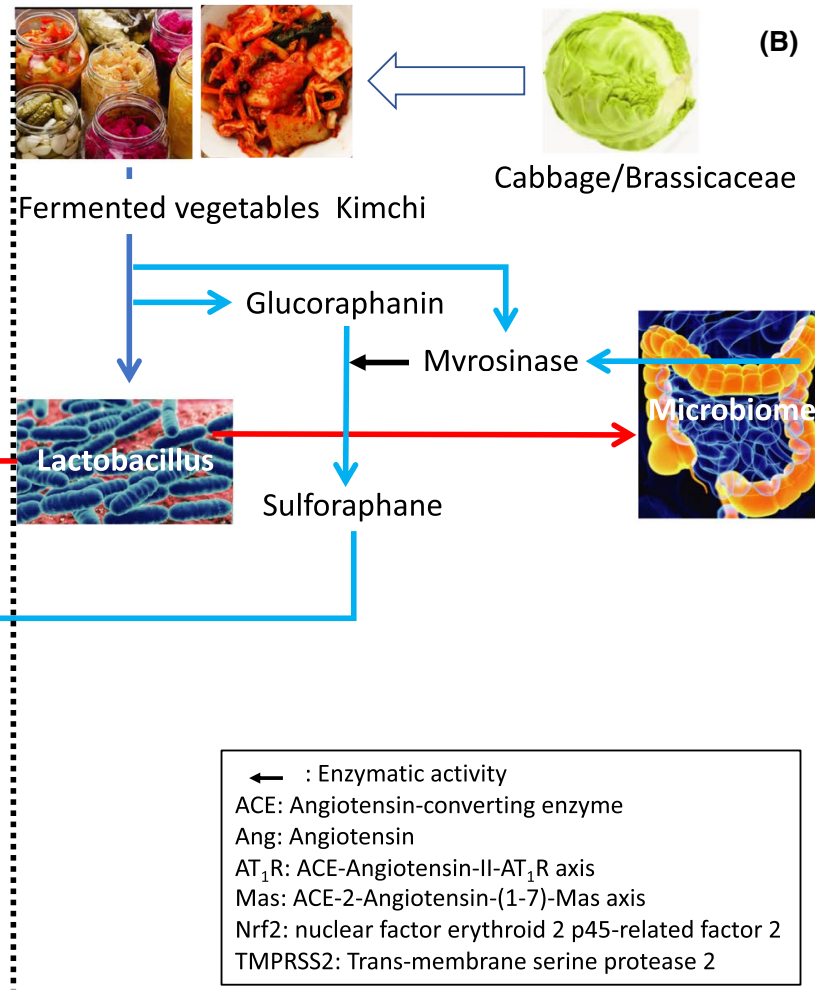

FIGURE 5 Putative mechanisms of fermented or Brassica vegetables against COVID-19. (A) Oxidative stress induced by SARS-CoV-2 after its binding to ACE2. (B) Preventive effects of cabbage and fermented vegetables through Nrf2 


\section{1 | Nrf2, a central antioxidant system}

Reactive oxygen species (ROS), such as hydrogen peroxide and superoxide anion, exert beneficial and toxic effects on cellular functions. Nrf2 is a pleiotropic transcription factor at the center of a complex regulatory network that protects against oxidative stress and the expression of a wide array of genes involved in immunity and inflammation, including antiviral actions. ${ }^{66} \mathrm{Nrf2}$ activity in response to chemical insults is regulated by a thiol-rich protein named KEAP1 (Kelch-like ECH-associated protein 1). The KEAP1Nrf2 system is the body's dominant defense mechanism against ROS. $^{67}$ Induction of the antioxidant responsive element and the ROS-mediated pathway by Nrf2 reduces the activity of the nu-

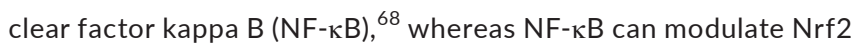
transcription and activity, having both positive and negative effects on the target gene expression. ${ }^{69}$

Natural compounds derived from plants, vegetables, fungi, and micronutrients (eg, curcumin, sulforaphane, resveratrol, and vitamin D) or physical exercise can activate Nrf2. ${ }^{70,71}$ However, sulforaphane is the most potent activator of Nrf2. 3,34 "Ancient foods," and particularly those containing Lactobacillus, activate Nrf2. ${ }^{72}$

Nrf2 may be involved in diseases associated with insulin resistance. ${ }^{60,73-75}$ Nrf2 activity declines with age, making the elderly more susceptible to oxidative stress-mediated diseases. ${ }^{76} \mathrm{Nrf2}$ is involved in the protection against lung ${ }^{77}$ or endothelial damage. ${ }^{78}$ Nrf2-activating compounds downregulate ACE2 mRNA expression in human liver-derived HepG2 cells. ${ }^{79}$ Genes encoding cytokines, including IL-6 and many others specifically identified in the "cytokine storm", have been observed in fatal cases of COVID-19. ACE2 can inhibit NF- $\mathrm{KB}$ and activate Nrf2. ${ }^{80}$

\subsection{Sulforaphane, the most potent Nrf2 natural activator}

Isothiocyanates are stress response chemicals formed from glucosinolates in plants often belonging to the cruciferous family, and, more broadly, to the Brassica genus including broccoli, watercress, kale, cabbage, collard greens, Brussels sprouts, bok choy, mustard greens, and cauliflower. ${ }^{81}$ The formation of isothiocyanates from glucosinolates depends on plant-intrinsic factors and -extrinsic postharvest factors such as industrial processing, domestic preparation, mastication, and digestion. ${ }^{82}$

Sulforaphane [1-isothiocyanato-4-(methylsulfinyl)butane] is an isothiocyanate occurring in a stored form such as glucoraphanin in cruciferous vegetables. ${ }^{83,84}$ Sulforaphanes are also found in fermented cabbage. ${ }^{31,85}$ Present in the plant as its precursor, glucoraphanin, sulforaphane is formed through the actions of myrosinase, a $\beta$-thioglucosidase present in either the plant tissue or the mammalian microbiome. ${ }^{86,87}$

Sulforaphane is a clinically relevant nutraceutical compound used for the prevention and treatment of chronic diseases and may be involved in aging. ${ }^{88}$ Along with other natural nutrients, sulforaphane has been suggested to have a therapeutic value for the treatment of coronavirus disease 2019 (COVID-19). ${ }^{89}$

One of the key mechanisms of action of sulforaphane involves the activation of the Nrf2-Keap1 signaling pathway. ${ }^{90}$ Sulforaphane is the most effective natural activator of the Nrf2 pathway, and Nrf2 expression and function are vital for sulforaphane-mediated action. ${ }^{91,92}$ Sulforaphanes were suggested to be effective in diseases associated with insulin resistance. ${ }^{1,93-95}$ It has been proposed that SARS-CoV-2 downregulates ACE2 and that there is an increased insulin resistance associated with oxidative stress through the $A T_{1} R$ pathway. Fermented vegetables and Brassica vegetables release glucoraphanin, converted by the plant or by the gut microbiome into sulforaphane, which activates Nrf2 and subsequently reduces insulin intolerance (Figure 5B).

\section{3 | Lactic acid bacteria}

\subsection{1 | Antioxidant activity of Lactobacillus}

The gastrointestinal (GI) tract is challenged with oxidative stress induced by a wide array of factors, such as exogenous pathogenic microorganisms and dietary aspects. Redox signaling plays a critical role in the physiology and pathophysiology of the GI tract. ${ }^{96}$ The redox mechanisms of Lactobacillus spp. are involved in the downregulation of ROS-forming enzymes, ${ }^{97,98}$ and redox stress resistance proteins or genes differ largely between LAB species. In addition, Nrf-2 and NF- $\mathrm{KB}$ are two common transcription factors, through which Lactobacillus spp. also modulates oxidative stress. ${ }^{99}$

\subsection{2 | Do lactobacilli prevent insulin resistance?}

Hundreds of studies have attempted to find an efficacy of LAB on insulin resistance-associated diseases. However, most of them are underpowered or have some methodological flaw. Moreover, not all $L A B$ strains have the same action on insulin resistance ${ }^{100}$ and new better designed studies with an appropriate $L A B$ are required. A large meta-analysis found that the intake of probiotics resulted in minor but consistent improvements in several metabolic risk factors in subjects with metabolic diseases, and particularly in insulin resistance. ${ }^{101}$ Another recent meta-analysis found that an oral supplementation with probiotics or synbiotics has a small effect in reducing waist circumference but no effect on body weight or body mass index (BMI). ${ }^{102}$ Kefir, a fermented milk product, was not found to be more effective than yoghurt in the glycemic control of obesity, possibly because there are insufficient differences between both. ${ }^{103}$

\subsection{3 | Lactobacillus and Nrf2}

Nrf2 may be involved in diseases associated with insulin resistance. $^{73-75}$ "Ancient foods," and particularly those containing 
Lactobacillus, activate Nrf2. ${ }^{72}$ The microbiome is highly related to insulin resistance. In mice, several strains of Lactobacillus were found to regulate Nrf2 in models of aging, ${ }^{104}$ in cardioprotective effects, ${ }^{105}$ and in nonalcoholic fatty acid liver disease. ${ }^{106}$ Lactobacillus plantarum CQPC11-isolated from Sichuan pickled cabbages-antagonizes oxidation and aging in mice. ${ }^{107}$ Lactobacillus protects against ulcerative colitis by modulation of the gut microbiota and Nrf2/Ho-1 pathway. ${ }^{108}$ The sugary kefir strain, Lactobacillus mali APS1, ameliorates hepatic steatosis by regulation of Nrf2 and the gut microbiota in rats. ${ }^{109}$ In vitro studies have also found an effect of Lactobacilli mediated by Nrf2. ${ }^{110-112}$ Interestingly, the symbiotic combination of prebiotic grape pomace extract and probiotic Lactobacillus sp reduces intestinal inflammatory markers. ${ }^{113}$

\subsubsection{Coronavirus disease in animals and lactic acid bacteria}

The porcine epidemic diarrhea virus (PEDV) and the transmissible gastroenteritis coronavirus infection (TGEV) are worldwide-distributed coronaviruses. Low levels of Lactobacillus were found in the intestine of piglets infected by TGEV ${ }^{114}$ or PEDV. Lactobacillus inhibits PEDV or TGEV effects in vitro. ${ }^{115,116}$

\section{4 | 7-4-Nrf2 and COVID-19}

Nrf2 can act on the endoplasmic reticulum stress and the AT1R pathway. A putative mechanism may be proposed for the AT1R pathway (Figure 5). SARS-CoV-2 downregulates ACE2, inducing an increased insulin resistance associated with oxidative stress through the $\mathrm{AT}_{1} \mathrm{R}$ pathway. This may explain risk factors for severe COVID-19.

Fermented vegetables are often made from cruciferous (Brassica) vegetables that release glucoraphanin converted by the plant or by the gut microbiome into sulforaphane which activates Nrf2 and subsequently reduces insulin intolerance by its potent antioxidant activities. Fermented vegetables contain a high content of Lactobacillus that can activate Nrf2 and impact on the microbiome. 117 Sulforaphane and LAB both therefore have the ability to reduce insulin resistance.

Other putative actions on COVID-19 severity may be postulated. The downregulation of ACE2 reduces the Ang-1,7 antioxidant activity that was found to activate Nrf2 ${ }^{118,119} \mathrm{Nrf2}$ protects against hallmarks of severe COVID-19. It has anti-fibrotic effects on various organs including the lungs, ${ }^{120}$ and protects against lung injury, acute respiratory distress syndrome, ${ }^{121}$ and endothelial damage. ${ }^{78}$ Finally, Nrf2 can block IL-6 in different models of inflammation ${ }^{122}$ and might play a role in the COVID-19 cytokine storm.

These different mechanisms may explain the importance of fermented cabbage in preventing the severity of COVID-19. It is clear that other nutrients, vitamin $\mathrm{D},{ }^{123}$ and many different foods act on NRF2 and that mechanisms other than Nrf2 may be operative.

It is not yet known whether sulforaphane and/or LAB may act on the infectivity of SARS-CoV-2. Disulfide bonds can be formed under oxidizing conditions and play an important role in the folding and stability of some proteins. The receptor-binding domain of the viral spike proteins and ACE2 both have several cysteine residues. Using molecular dynamics simulations, the binding affinity was significantly impaired when all of the disulfide bonds of both ACE2 and SARS-CoV/CoV-2 spike proteins were reduced to thiol groups. This computational finding possibly provides a molecular basis for the differential COVID-19 cellular recognition due to the oxidative stress. ${ }^{124}$

It is likely that foods with antioxidant activity can interact with COVID-19 and that fermented or cruciferous vegetables represent one of the possible foods involved. If some foods are found to be associated with a prevention of COVID-19 prevalence or severity, it may be of interest to study their $L A B$ and/or sulforaphane composition in order to eventually find some common mechanisms and targets for therapy.

\section{9 | MAY DIETARY MODIFICATIONS CHANGE THE COURSE OF COVID-19?}

\subsection{Fermented vegetables and Kimchi}

It is tempting to propose that countries where traditional LABfermented vegetables are largely consumed are those showing lower COVID-19 death rates and that fermented vegetables represent one possible preventive approach. Other nutrients are found in these products that may enhance their effect (eg, vitamin $\mathrm{K}^{125}$ ). Kimchi fermented from many vegetables including cabbage has several effects on insulin resistance-associated diseases: anti-diabetic properties, ${ }^{126,127}$ cardiovascular diseases, ${ }^{28}$ dyslipidemia, ${ }^{128}$ or aging. ${ }^{129}$ Kimchi, when fermented for a long time, reduces insulin intolerance to a greater extent than fresh kimchi, ${ }^{126}$ indicating that newly formed products during fermentation are important. In particular, Kimchi from cabbage and Chinese cabbage contains several glucosinolates ${ }^{60,130,131}$ that can be transformed into sulforaphanes either in the plant itself or by the human microbiome. ${ }^{60}$ In central European countries, raw and fermented cabbage is commonly consumed.

In sub-Saharan Africa, although young age is an important factor, people commonly eat fermented foods, mainly cereal-based foods like sorghum, millet and maize, and roots such as cassava, fruits, and vegetables. Fermented cassava products (like gari and fufu) are a major component of the diet of over 800 million people and, in some areas, these products constitute over $50 \%$ of the diet. ${ }^{16}$

It is clear that sauerkraut is consumed in Alsace (France) where a COVID-19 outbreak has been identified, but it is not a regular meal. 


\section{2 | Westernized diet}

Westernized diets contain reduced amounts of fermented vegetables $^{43,132}$ and the population may be prone to increasing insulin resistance $^{44,133}$, to diseases associated with it, ${ }^{134}$ and thereby to severe COVID-19.

In the Mediterranean diet, well known for reducing insulin resistance, ${ }^{135}$ Nrf2 appears to play an important role. ${ }^{71,136}$ The COVID19 death rate differences in Italian (Figure 2) and Spanish ${ }^{3}$ regions suggest a role for Mediterranean diet and short-chain food supply. This also indicates that many foods can have an effect and that cabbage and fermented foods represent a proof-of-concept. Nrf2 is also involved in the Okinawan-based diet, ${ }^{71}$ active on insulin intolerance. ${ }^{137}$ Taken altogether, it is possible that diet is partly involved in the COVID-19 death clusters found in large Western cities where traditional diet is often replaced by long-chain food supply.

It is clear that diet is not the only risk factor and should be considered in the context of COVID-19 in a given setting. For example, Nordic/central European people socialize less than the Mediterraneans and simultaneously may consume more fermented vegetables.

\section{3 | The COVID-19 slum paradox}

It was expected that the COVID-19 pandemic would be catastrophic if it reached deprived areas of low- and middle-income countries, in particular informal settlements (slum areas) where social distancing and lockdown are almost impossible to set up. ${ }^{138}$

In the United States, highly populated, regional air hub areas, minorities, and poverty had an increased risk of COVID-19-related mortality. ${ }^{139}$ It was proposed that the inequality might be due to the workforce of essential services, poverty, access to care, or air pollution. ${ }^{140}$ These are common risk factors in mortality observed in deprived areas of the United States. ${ }^{141}$ Moreover, in the United States and the UK, there are unique health issues facing black, Asian, and minority ethnic communities. ${ }^{142,143}$ This greater risk of hospitalization in these populations was not explained by socioeconomic or behavioral factors. ${ }^{144}$ Social distancing is an important factor to be considered ${ }^{145}$ but diet may also be involved.

On the other hand, a recent report of the Municipal Corporation of Greater Mumbai (Public Relation Department, 28-07-2020) found that $57 \%$ of subjects tested in the slum area had antibodies against SARS-CoV-2 but only $16 \%$ in the nonslum areas. The fatality rate in slum areas was very low (0.05\%-0.1\%). ${ }^{146}$ Although precise data are lacking, in Brazilian favelas, the spread of COVID-19 is not noticed. ${ }^{147}$ Temperature does not seem to be an important factor for containing the pandemic. Young age of the population may be important. Fermented foods are popular throughout the world, and, in many regions, they represent a widespread tradition. They also contribute significantly to the diet of millions of individuals. ${ }^{16}$ This is the case in slum areas, and it is possible that fermented foods may explain, at least partly, the paradox.

\section{Social distancing, age (population, individual), lockdown, sex, other factors}

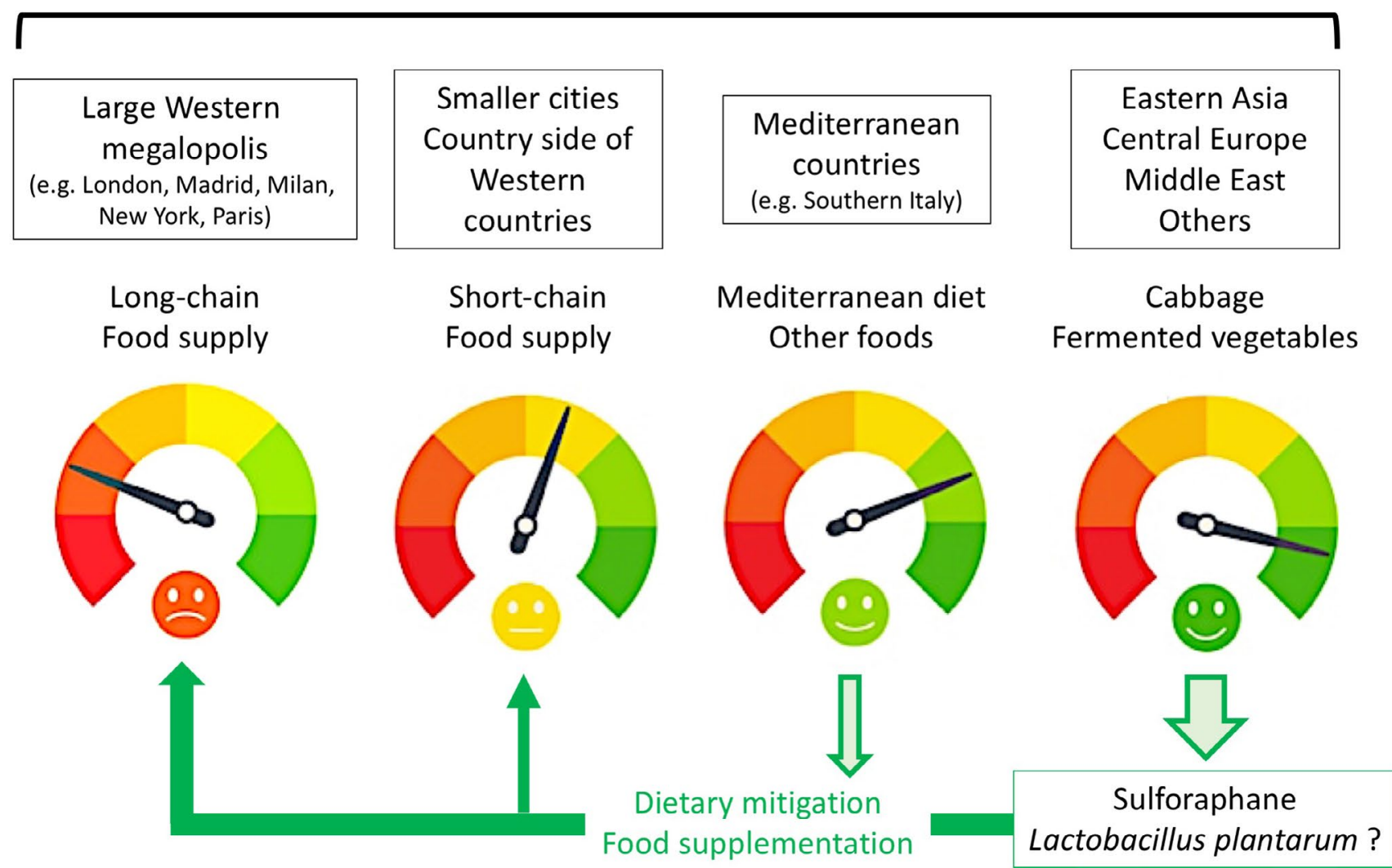

FIGURE 6 Putative role of diet in COVID-19 


\section{0 | CONCLUSION}

Cabbage contains precursors of sulforaphane, the most active natural activator of Nrf2. Fermented vegetables contain many lactobacilli, also potent Nrf2 activators. It is proposed that fermented cabbage is a proof-of-concept of dietary manipulations that may enhance Nrf2associated antioxidant effects helpful in mitigating COVID-19 severity.

Mainstream COVID-19 control strategies including social distancing, confinement, intensive case finding, testing, tracing, and isolating are so far not enough to provide a SARS-CoV-2-free environment and restore a safe social life. There are hopes for a safe and effective vaccine, but this is unlikely to become rapidly available. So, there is a need to explore other potentially useful strategies. An area that has not been sufficiently considered is diet, both as a preventive and therapeutically useful intervention, encouraging people to eat more traditional foods containing fermented vegetables (Figure 6). We have suggested that fermented vegetables could be associated with a lower COVID-19 mortality due to their potent antioxidant effect among which sulforaphane and $L A B$ are important. However, many other foods may have a similar activity. It should be noted that dietary supplements that overactivate Nrf2 may have side effects. ${ }^{148}$

Robust evidence from observational studies would be helpful to formally investigate associations between fermented foods and clinical outcomes in COVID-19. State-of-the-art methods, including the use of DAGs (directed acyclic graphs), may be needed to help assess whether the associations seen are likely to represent causal relationship. ${ }^{149} \mathrm{~A}$ faster approach would be to develop large clinical trials in the appropriate populations. Interventions based on diets with a high intake of fermented foods like Kimchi or other fermented foods are unlikely to present ethical difficulties. Furthermore, the fact that a precise mechanism has been proposed would facilitate adding reliable biomarkers to the relevant clinical outcomes. Moreover, new drugs based on the components of these fermented foods may be of interest.

If the hypothesis is proved, COVID-19 will be the first infectious disease outbreak associated with a loss of "nature"150 and to be ascribed as a disease of the Anthropocene. ${ }^{151}$ Imbalance in the gut microbiota is responsible for the pathogenesis of various disease types including allergy, asthma, rheumatoid arthritis, different types of cancer, diabetes mellitus, obesity, and cardiovascular disease. ${ }^{152}$ Fermentation was introduced during the Neolithic age and was essential for the survival of humankind. When modern life led to eating reduced amounts of fermented foods, the microbiome drastically changed, ${ }^{153}$ allowing SARS-CoV-2 to spread or to be more severe. ${ }^{154}$ It is time for mitigation. ${ }^{155}$

\section{CONFLICT OF INTEREST}

The authors have no conflict of interest to declare.

\section{ORCID}

Tari Haahtela (iD https://orcid.org/0000-0003-3673-8333

Cezmi A. Akdis (D) https://orcid.org/0000-0001-8020-019X

Torsten Zuberbier iD https://orcid.org/0000-0002-1466-8875

\section{REFERENCES}

1. Stafford N. Covid-19: Why Germany's case fatality rate seems so low. BMJ. 2020;369:m1395.

2. Bousquet J, Czarlewski W, Blain H, Zuberbier T, Anto J. Rapid Response: Why Germany's case fatality rate seems so low: Is nutrition another possibility. BMJ. 2020. https://www.bmj.com/conte nt/369/bmj.m1395/rr-12

3. Bousquet J, Anto JM, laccarino $\mathrm{G}$, et al. Is diet partly responsible for differences in COVID-19 death rates between and within countries? Clin Transl Allergy. 2020;10:16.

4. Iddir M, Brito A, Dingeo G, et al. Strengthening the Immune System and Reducing Inflammation and Oxidative Stress through Diet and Nutrition: Considerations during the COVID-19 Crisis. Nutrients. 2020;12(6):1562.

5. Cena H, Chieppa M. Coronavirus Disease (COVID-19-SARS-CoV-2) and Nutrition: Is Infection in Italy Suggesting a Connection? Front Immunol. 2020;11:944.

6. Infusino F, Marazzato M, Mancone M, et al. Diet Supplementation, Probiotics, and Nutraceuticals in SARS-CoV-2 Infection: A Scoping Review. Nutrients. 2020;12(6):1718.

7. Adams KK, Baker WL, Sobieraj DM. Myth busters: dietary supplements and COVID-19. Ann Pharmacother. 2020;54:820-826.

8. Sunyer J, Jarvis D, Pekkanen J, et al. Geographic variations in the effect of atopy on asthma in the European Community Respiratory Health Study. J Allergy Clin Immunol. 2004;114:1033-1039.

9. Kissler SM, Tedijanto C, Goldstein E, Grad YH, Lipsitch M. Projecting the transmission dynamics of SARS-CoV-2 through the postpandemic period. Science. 2020;368(6493):860-868.

10. Rosenthal PJ, Breman JG, Djimde AA, et al. COVID-19: Shining the Light on Africa. Am J Trop Med Hyg. 2020;102(6):1145-1148.

11. Fonseca S, Rivas I, Romaguera D, et al.Association between consumption of fermented vegetables and COVID-19 mortality at a country level in Europe MEDRXIV/2020/147025; 2020.

12. Fonseca S, Rivas I, Romaguera D, et al. Association between consumption of vegetables and COVID-19 mortality at a country level in Europe. MedRix. 2020. https://doi.org/10.1101/2020. 07.17.20155846

13. Baker P, Friel S. Food systems transformations, ultra-processed food markets and the nutrition transition in Asia. Global Health. 2016;12:80

14. Santulli G, Pascale V, Finelli R, et al. We are What We Eat: Impact of Food from Short Supply Chain on Metabolic Syndrome. J Clin Med. 2019;8(12):2061.

15. Peters A, Krumbholz P, Jager E, et al. Metabolites of lactic acid bacteria present in fermented foods are highly potent agonists of human hydroxycarboxylic acid receptor 3. PLoS Genet. 2019;15:e1008145.

16. Azam-Ali S. Fermented fruits and vegetables. A global perspective; 1998.

17. Marco ML, Heeney D, Binda S, et al. Health benefits of fermented foods: microbiota and beyond. Curr Opin Biotechnol. 2017:44:94-102.

18. Rhee SJ, Lee JE, Lee CH. Importance of lactic acid bacteria in Asian fermented foods. Microb Cell Fact. 2011;10(Suppl 1):S5.

19. Patra JK, Das G, Paramithiotis S, Shin HS. Kimchi and other widely consumed traditional fermented foods of korea: a review. Front Microbiol. 2016;7:1493.

20. Jung JY, Lee SH, Jeon CO. Kimchi microflora: history, current status, and perspectives for industrial kimchi production. Appl Microbiol Biotechnol. 2014;98:2385-2393.

21. Chen YS, Otoguro M, Lin YH, et al. Lactococcus formosensis sp. nov., a lactic acid bacterium isolated from yan-tsai-shin (fermented broccoli stems). Int J Syst Evol Microbiol. 2014;64:146-151.

22. Han X, Yi H, Zhang L, et al. Improvement of fermented Chinese cabbage characteristics by selected starter cultures. J Food Sci. 2014;79:M1387-M1392. 
23. Yoon KY, Woodams EE, Hang YD. Production of probiotic cabbage juice by lactic acid bacteria. Bioresour Technol. 2006;97:1427-1430.

24. Slattery C, Cotter PD, O'Toole PW. Analysis of health benefits conferred by Lactobacillus species from Kefir. Nutrients. 2019;11(6):1252.

25. Shiby VK, Mishra HN. Fermented milks and milk products as functional foods-a review. Crit Rev Food Sci Nutr. 2013;53:482-496.

26. Sanders ME, Merenstein DJ, Reid G, Gibson GR, Rastall RA. Probiotics and prebiotics in intestinal health and disease: from biology to the clinic. Nat Rev Gastroenterol Hepatol. 2019;16:605-616.

27. Sanlier N, Gokcen BB, Sezgin AC. Health benefits of fermented foods. Crit Rev Food Sci Nutr. 2019;59:506-527.

28. Lavefve L, Marasini D, Carbonero F. Microbial ecology of fermented vegetables and non-alcoholic drinks and current knowledge on their impact on human health. Adv Food Nutr Res. 2019;87:147-185.

29. Melini F, Melini V, Luziatelli F, Ficca AG, Ruzzi M. Health-Promoting Components in Fermented Foods: An Up-to-Date Systematic Review. Nutrients. 2019;11(5):1189.

30. Azam M, Mohsin M, ljaz H, et al. Review - Lactic acid bacteria in traditional fermented Asian foods. Pak J Pharm Sci. 2017;30:1803-1814.

31. Dimidi E, Cox SR, Rossi M, Whelan K. Fermented foods: definitions and characteristics, impact on the gut microbiota and effects on gastrointestinal health and disease. Nutrients. 2019;11(8):1806.

32. Riggioni $C$, Comberiati $P$, Giovannini $M$, et al. A compendium answering 150 questions on COVID-19 and SARS-CoV-2. Allergy. 2020;75:2503-2541. https://doi.org/10.1111/all.14449

33. Ruokolainen L, Lehtimäki J, Karkman A, Haahtela T. Holistic view on health : two protective layers of biodiversity. Ann Zool Fennici. 2017;54:39-49.

34. Septembre-Malaterre A, Remize F, Poucheret P. Fruits and vegetables, as a source of nutritional compounds and phytochemicals: Changes in bioactive compounds during lactic fermentation. Food Res Int. 2018;104:86-99.

35. Kok CR, Hutkins R. Yogurt and other fermented foods as sources of health-promoting bacteria. Nutr Rev. 2018;76:4-15.

36. De Filippis F, Pasolli E, Ercolini D. The food-gut axis: lactic acid bacteria and their link to food, the gut microbiome and human health. FEMS Microbiol Rev. 2020;44(4):454-489.

37. Mobeen F, Sharma V, Tulika P. Enterotype Variations of the Healthy Human Gut Microbiome in Different Geographical Regions. Bioinformation. 2018;14:560-573.

38. Bibbo S, laniro G, Giorgio V, et al. The role of diet on gut microbiota composition. Eur Rev Med Pharmacol Sci. 2016;20:4742-4749.

39. Tian S, Liu X, Lei P, Zhang X, Shan Y. Microbiota: a mediator to transform glucosinolate precursors in cruciferous vegetables to the active isothiocyanates. J Sci Food Agric. 2018;98:1255-1260.

40. Segata N. Gut Microbiome: Westernization and the Disappearance of Intestinal Diversity. Curr Biol. 2015;25:R611-R613.

41. Vangay P, Johnson AJ, Ward TL, et al. US Immigration Westernizes the Human Gut Microbiome. Cell. 2018;175:962-972.

42. Zuo T, Kamm MA, Colombel JF, Ng SC. Urbanization and the gut microbiota in health and inflammatory bowel disease. Nat Rev Gastroenterol Hepatol. 2018;15:440-452.

43. Wilson AS, Koller KR, Ramaboli MC, et al. Diet and the human gut microbiome: an international review. Dig Dis Sci. 2020;65: 723-740.

44. Yamashita M, Okubo $\mathrm{H}$, Kobuke $\mathrm{K}$, et al. Alteration of gut microbiota by a Westernized lifestyle and its correlation with insulin resistance in non-diabetic Japanese men. J Diabetes Investig. 2019;10:1463-1470.

45. Angelakis E, Yasir M, Bachar D, et al. Gut microbiome and dietary patterns in different Saudi populations and monkeys. Sci Rep. 2016;6:32191.
46. Mitsou EK, Kakali A, Antonopoulou S, et al. Adherence to the Mediterranean diet is associated with the gut microbiota pattern and gastrointestinal characteristics in an adult population. $\mathrm{Br} \mathrm{J}$ Nutr. 2017;117:1645-1655.

47. Saad MJ, Santos A, Prada PO. Linking Gut Microbiota and Inflammation to Obesity and Insulin Resistance. Physiology. 2016;31:283-293.

48. Chen X, Devaraj S. Gut microbiome in obesity, metabolic syndrome, and diabetes. Curr Diab Rep. 2018;18:129.

49. Lee CJ, Sears CL, Maruthur N. Gut microbiome and its role in obesity and insulin resistance. Ann N Y Acad Sci. 2020;1461:37-52.

50. Zuo T, Zhang F, Lui GCY, et al. Alterations in Gut microbiota of patients with COVID-19 during time of hospitalization. Gastroenterology. 2020. https://doi.org/10.1053/j.gastro.2020. 05.048

51. Xu K, Cai H, Shen Y, et al. Management of Corona Virus disease-19 (COVID-19): The zhejiang experience. Zhejiang Da Xue Xue Bao Yi Xue Ban. 2020;49.

52. Finucane FM, Davenport C. Coronavirus and obesity: could insulin resistance mediate the severity of Covid-19 infection? Front Public Health. 2020;8:184.

53. Guzik TJ, Cosentino F. Epigenetics and Immunometabolism in Diabetes and Aging. Antioxid Redox Signal. 2018;29:257-274.

54. Miedema MD, Maziarz M, Biggs ML, et al. Plasma-free fatty acids, fatty acid-binding protein 4, and mortality in older adults (from the Cardiovascular Health Study). Am J Cardiol. 2014;114:843-848.

55. Hurrle S, Hsu WH. The etiology of oxidative stress in insulin resistance. Biomed J. 2017;40:257-262.

56. Wen H, Gwathmey JK, Xie LH. Oxidative stress-mediated effects of angiotensin II in the cardiovascular system. World J Hypertens. 2012;2:34-44.

57. Bhatt SR, Lokhandwala MF, Banday AA. Vascular oxidative stress upregulates angiotensin II type I receptors via mechanisms involving nuclear factor kappa B. Clin Exp Hypertens. 2014;36:367-373.

58. Dalan R, Bornstein SR, El-Armouche A, et al. The ACE-2 in COVID19: Foe or Friend? Horm Metab Res. 2020;52:257-263.

59. Sarzani R, Giulietti F, Di Pentima C, Giordano P, Spannella F. Disequilibrium between the classic renin-angiotensin system and its opposing arm in Sars-Cov-2 related lung injury. Am J Physiol Lung Cell Mol Physiol. 2020;319(2):L325-L336.

60. Bousquet J, Anto J, Czarlewski W, et al. Sulforaphane: from death rate heterogeneity in countries to candidate for prevention of severe COVID-19. Allergy. 2020. https://doi.org/10.22541/au.15949 3397.79345039

61. Ren H, Yang Y, Wang F, et al. Association of the insulin resistance marker TyG index with the severity and mortality of COVID-19. Cardiovasc Diabetol. 2020;19:58.

62. Jain S, Buttar HS, Chintameneni M, Kaur G. Prevention of cardiovascular diseases with anti-inflammatory and anti- oxidant nutraceuticals and herbal products: an overview of pre-clinical and clinical studies. Recent Pat Inflamm Allergy Drug Discov. 2018;12:145-157.

63. Razmpoosh E, Javadi M, Ejtahed HS, Mirmiran P. Probiotics as beneficial agents in the management of diabetes mellitus: a systematic review. Diabetes Metab Res Rev. 2016;32:143-168.

64. Serino A, Salazar G. Protective role of polyphenols against vascular inflammation, aging and cardiovascular disease. Nutrients. 2019;11(1):53.

65. Zabetakis I, Lordan R, Norton C, Tsoupras A. COVID-19: The inflammation link and the role of nutrition in potential mitigation. Nutrients. 2020;12(5):1466.

66. Tonelli C, Chio IIC, Tuveson DA. Transcriptional regulation by Nrf2. Antioxid Redox Signal. 2018;29:1727-1745.

67. Yamamoto M, Kensler TW, Motohashi H. The KEAP1-NRF2 system: a thiol-based sensor-effector apparatus for maintaining redox homeostasis. Physiol Rev. 2018;98:1169-1203. 
68. Cuadrado A, Pajares $M$, Benito $C$, et al. Can Activation of NRF2 Be a Strategy against COVID-19? Trends Pharmacol Sci. 2020;41(9):598-610.

69. Wardyn JD, Ponsford AH, Sanderson CM. Dissecting molecular cross-talk between Nrf2 and NF-kappaB response pathways. Biochem Soc Trans. 2015;43:621-626.

70. Jimenez-Osorio AS, Gonzalez-Reyes S, Pedraza-Chaverri J. Natural Nrf2 activators in diabetes. Clin Chim Acta. 2015;448:182-192.

71. Pall ML, Levine S. Nrf2, a master regulator of detoxification and also antioxidant, anti-inflammatory and other cytoprotective mechanisms, is raised by health promoting factors. Sheng Li Xue Bao. 2015;67:1-18.

72. Senger DR, Li D, Jaminet SC, Cao S. Activation of the Nrf2 Cell defense pathway by ancient foods: disease prevention by important molecules and microbes lost from the modern western diet. PLoS One. 2016;11:e0148042.

73. Uruno A, Yagishita Y, Yamamoto M. The Keap1-Nrf2 system and diabetes mellitus. Arch Biochem Biophys. 2015;566:76-84.

74. Vasileva LV, Savova MS, Amirova KM, Dinkova-Kostova AT, Georgiev MI. Obesity and NRF2-mediated cytoprotection: Where is the missing link? Pharmacol Res. 2020;156:104760.

75. Guo Z, Mo Z. Keap1-Nrf2 signaling pathway in angiogenesis and vascular diseases. J Tissue Eng Regen Med. 2020;14:869-883.

76. Zhang H, Davies KJA, Forman HJ. Oxidative stress response and Nrf2 signaling in aging. Free Radic Biol Med. 2015;88:314-336.

77. Rojo de la Vega M, Dodson M, Gross C, et al. Role of Nrf2 and autophagy in acute lung injury. Curr Pharmacol Rep. 2016;2:91-101.

78. Chen B, Lu Y, Chen Y, Cheng J. The role of Nrf2 in oxidative stress-induced endothelial injuries. J Endocrinol. 2015;225:R83-R99.

79. McCord JM, Hybertson BM, Cota-Gomez A, Gao B. Nrf2 Activator $\mathrm{PB} 125(\mathrm{R})$ as a potential therapeutic agent against COVID-19. bioRxiv 2020. https://doi.org/10.1101/2020.05.16.099788

80. Fang Y, Gao F, Liu Z. Angiotensin-converting enzyme 2 attenuates inflammatory response and oxidative stress in hyperoxic lung injury by regulating NF-kappaB and Nrf2 pathways. QJM. 2019;112:914-924.

81. Palliyaguru DL, Yuan JM, Kensler TW, Fahey JW. Isothiocyanates: Translating the Power of Plants to People. Mol Nutr Food Res. 2018;62:e1700965.

82. Oliviero T, Verkerk R, Dekker M. Isothiocyanates from Brassica vegetables-effects of processing, cooking, mastication, and digestion. Mol Nutr Food Res. 2018;62:e1701069.

83. Vanduchova A, Anzenbacher P, Anzenbacherova E. Isothiocyanate from Broccoli, Sulforaphane, and Its Properties. J Med Food. 2019;22:121-126.

84. Quirante-Moya S, Garcia-Ibanez P, Quirante-Moya F, Villano D, Moreno DA. The role of brassica bioactives on human health: are we studying it the right way? Molecules 2020;25(7):1591.

85. Luang-In V, Deeseenthum S, Udomwong P, Saengha W, Gregori M. Formation of sulforaphane and iberin products from thai cabbage fermented by myrosinase-positive bacteria. Molecules. 2018;23(4):955.

86. Yagishita Y, Fahey JW, Dinkova-Kostova AT, Kensler TW. Broccoli or sulforaphane: is it the source or dose that matters? Molecules. 2019;24(19):3593.

87. Hindson J. Brassica vegetable metabolism by gut microbiota. Nat Rev Gastroenterol Hepatol. 2020;17:195.

88. Houghton CA. Sulforaphane: Its "Coming of Age" as a clinically relevant nutraceutical in the prevention and treatment of chronic disease. Oxid Med Cell Longev. 2019;2019:2716870.

89. Horowitz RI, Freeman PR. Three novel prevention, diagnostic, and treatment options for COVID-19 urgently necessitating controlled randomized trials. Med Hypotheses. 2020;143:109851.

90. Yang L, Palliyaguru DL, Kensler TW. Frugal chemoprevention: targeting Nrf2 with foods rich in sulforaphane. Semin Oncol. 2016;43:146-153.
91. Bai Y, Wang X, Zhao S, Ma C, Cui J, Zheng Y. Sulforaphane protects against cardiovascular disease via Nrf2 Activation. Oxid Med Cell Longev. 2015;2015:407580.

92. Zhou S, Wang J, Yin X, et al. Nrf2 expression and function, but not MT expression, is indispensable for sulforaphane-mediated protection against intermittent hypoxia-induced cardiomyopathy in mice. Redox Biol. 2018;19:11-21.

93. Xu L, Nagata N, Ota T. Glucoraphanin: a broccoli sprout extract that ameliorates obesity-induced inflammation and insulin resistance. Adipocyte. 2018;7:218-225.

94. Teng W, Li Y, Du M, Lei X, Xie S, Ren F. Sulforaphane prevents hepatic insulin resistance by blocking serine palmitoyltransferase 3-mediated ceramide biosynthesis. Nutrients. 2019;11(5):1185.

95. Sun Y, Zhou S, Guo H, et al. Protective effects of sulforaphane on type 2 diabetes-induced cardiomyopathy via AMPK-mediated activation of lipid metabolic pathways and NRF2 function. Metabolism. 2020;102:154002.

96. Perez S, Talens-Visconti R, Rius-Perez S, Finamor I, Sastre J. Redox signaling in the gastrointestinal tract. Free Radic Biol Med. 2017;104:75-103.

97. An H, Zhai Z, Yin S, Luo Y, Han B, Hao Y. Coexpression of the superoxide dismutase and the catalase provides remarkable oxidative stress resistance in Lactobacillus rhamnosus. J Agric Food Chem. 2011;59:3851-3856.

98. Serata M, lino T, Yasuda E, Sako T. Roles of thioredoxin and thioredoxin reductase in the resistance to oxidative stress in Lactobacillus casei. Microbiology. 2012;158:953-962.

99. Kong Y, Olejar KJ, On SLW, Chelikani V. The Potential of Lactobacillus spp. for Modulating Oxidative Stress in the Gastrointestinal Tract. Antioxidants 2020;9(7):610.

100. Lee E, Jung SR, Lee SY, Lee NK, Paik HD, Lim SI. Lactobacillus plantarum Strain Ln4 Attenuates diet-induced obesity, insulin resistance, and changes in hepatic mRNA levels associated with glucose and lipid metabolism. Nutrients. 2018;10(5):643.

101. Koutnikova H, Genser B, Monteiro-Sepulveda M, et al. Impact of bacterial probiotics on obesity, diabetes and non-alcoholic fatty liver disease related variables: a systematic review and meta-analysis of randomised controlled trials. BMJ Open. 2019;9:e017995.

102. Suzumura EA, Bersch-Ferreira AC, Torreglosa CR, et al. Effects of oral supplementation with probiotics or synbiotics in overweight and obese adults: a systematic review and meta-analyses of randomized trials. Nutr Rev. 2019;77:430-450.

103. Barengolts E, Smith ED, Reutrakul S, Tonucci L, Anothaisintawee T. The effect of probiotic yogurt on glycemic control in type 2 diabetes or obesity: a meta-analysis of nine randomized controlled trials. Nutrients. 2019;11(3):671.

104. Li B, Evivie SE, Lu J, et al. Lactobacillus helveticus KLDS1.8701 alleviates d-galactose-induced aging by regulating Nrf-2 and gut microbiota in mice. Food Funct. 2018;9:6586-6598.

105. Xu H, Wang J, Cai J, et al. Protective Effect of Lactobacillus rhamnosus GG and its Supernatant against Myocardial Dysfunction in Obese Mice Exposed to Intermittent Hypoxia is Associated with the Activation of Nrf2 Pathway. Int J Biol Sci. 2019;15:2471-2483.

106. Zhao Z, Wang C, Zhang L, et al. Lactobacillus plantarum NA136 improves the non-alcoholic fatty liver disease by modulating the AMPK/ Nrf2 pathway. Appl Microbiol Biotechnol. 2019;103:5843-5850.

107. Qian Y, Zhang J, Zhou X, et al. Lactobacillus plantarum CQPC11 isolated from sichuan pickled cabbages antagonizes d-galactose-induced oxidation and aging in mice. Molecules. 2018;23(11):3026.

108. El-Baz AM, Khodir AE, Adel El-Sokkary MM, Shata A. The protective effect of Lactobacillus versus 5 -aminosalicylic acid in ulcerative colitis model by modulation of gut microbiota and Nrf2/Ho-1 pathway. Life Sci. 2020;256:117927.

109. Chen YT, Lin YC, Lin JS, Yang NS, Chen MJ. Sugary Kefir Strain Lactobacillus mali APS1 ameliorated hepatic steatosis by 
regulation of SIRT-1/Nrf-2 and gut microbiota in rats. Mol Nutr Food Res. 2018;62:e1700903.

110. Xu C, Qiao L, Ma L, et al. Biogenic selenium nanoparticles synthesized by Lactobacillus casei ATCC 393 alleviate intestinal epithelial barrier dysfunction caused by oxidative stress via Nrf2 signaling-mediated mitochondrial pathway. Int J Nanomedicine. 2019;14:4491-4502.

111. Mu G, Li H, Tuo Y, Gao Y, Zhang Y. Antioxidative effect of Lactobacillus plantarum Y44 on 2,2'-azobis(2-methylpropionamidine) dihydrochloride (ABAP)-damaged Caco-2 cells. J Dairy Sci. 2019;102:6863-6875.

112. Kobatake E, Nakagawa H, Seki T, Miyazaki T. Protective effects and functional mechanisms of Lactobacillus gasseri SBT2055 against oxidative stress. PLoS One. 2017;12:e0177106.

113. Pistol GC, Marin DE, Dragomir C, Taranu I. Synbiotic combination of prebiotic grape pomace extract and probiotic Lactobacillus sp. reduced important intestinal inflammatory markers and in-depth signalling mediators in lipopolysaccharide-treated Caco-2 cells. $\mathrm{Br}$ J Nutr. 2018;1-15.

114. Xia L, Yang Y, Wang J, Jing Y, Yang Q. Impact of TGEV infection on the pig small intestine. Virol J. 2018;15:102.

115. Kumar R, Seo BJ, Mun MR, et al. Putative probiotic Lactobacillus spp. from porcine gastrointestinal tract inhibit transmissible gastroenteritis coronavirus and enteric bacterial pathogens. Trop Anim Health Prod. 2010;42:1855-1860.

116. Zhang X, Li P, Zheng Q, Hou J. Lactobacillus acidophilus S-layer protein-mediated inhibition of PEDV-induced apoptosis of Vero cells. Vet Microbiol. 2019;229:159-167.

117. Hassan SM, Jawad MJ, Ahjel SW, et al. The Nrf2 Activator (DMF) and Covid-19: is there a possible role? Med Arch. 2020;74:134-138.

118. Romero A, San Hipolito-Luengo A, Villalobos LA, et al. The angiotensin-(1-7)/Mas receptor axis protects from endothelial cell senescence via klotho and Nrf2 activation. Aging Cell. 2019;18:e12913.

119. Cai SM, Yang RQ, Li Y, et al. Angiotensin-(1-7) Improves Liver Fibrosis by Regulating the NLRP3 Inflammasome via Redox Balance Modulation. Antioxid Redox Signal. 2016;24:795-812.

120. Liu Q, Gao Y, Ci X. Role of Nrf2 and its activators in respiratory diseases. Oxid Med Cell Longev. 2019;2019:7090534.

121. Zhao H, Eguchi S, Alam A, Ma D. The role of nuclear factor-erythroid 2 related factor 2 (Nrf-2) in the protection against lung injury. Am J Physiol Lung Cell Mol Physiol. 2017;312:L155-L162.

122. Keleku-Lukwete N, Suzuki M, Yamamoto M. an overview of the advantages of KEAP1-NRF2 system activation during inflammatory disease treatment. Antioxid Redox Signal. 2018;29:1746-1755.

123. Mitchell F. Vitamin-D and COVID-19: do deficient risk a poorer outcome? Lancet Diabetes Endocrinol. 2020;8:570.

124. Hati S, Bhattacharyya S. Impact of thiol-disulfide balance on the binding of Covid-19 spike protein with angiotensin-converting enzyme 2 Receptor. ACS Omega. 2020;5:16292-16298.

125. Tarvainen M, Fabritius M, Yang B. Determination of vitamin $K$ composition of fermented food. Food Chem. 2019;275:515-522.

126. An SY, Lee MS, Jeon JY, et al. Beneficial effects of fresh and fermented kimchi in prediabetic individuals. Ann Nutr Metab. 2013;63:111-119.

127. Kim EK, An SY, Lee MS, et al. Fermented kimchi reduces body weight and improves metabolic parameters in overweight and obese patients. Nutr Res. 2011;31:436-443.

128. Kim SA, Joung H, Shin S. Dietary pattern, dietary total antioxidant capacity, and dyslipidemia in Korean adults. Nutr J. 2019;18:37.

129. Das G, Paramithiotis S, Sundaram Sivamaruthi B, et al. Traditional fermented foods with anti-aging effect: A concentric review. Food Res Int. 2020;134:109269.

130. Hong E, Kim GH. GC-MS Analysis of the Extracts from Korean Cabbage (Brassica campestris L. ssp. pekinensis) and Its Seed. Prev Nutr Food Sci. 2013;18:218-221.
131. Park CH, Yeo HJ, Park SY, Kim JK, Park SU. Comparative Phytochemical Analyses and Metabolic Profiling of Different Phenotypes of Chinese Cabbage (Brassica Rapa ssp. Pekinensis). Foods. 2019;8(11):587.

132. Raghuvanshi R, Grayson AG, Schena I, Amanze O, Suwintono K, Quinn RA. Microbial transformations of organically fermented foods. Metabolites. 2019;9(8):165.

133. O'Dea K. Westernization and non-insulin-dependent diabetes in Australian Aborigines. Ethn Dis. 1991;1:171-187.

134. Kopp W. How western diet and lifestyle drive the pandemic of obesity and civilization diseases. Diabetes Metab Syndr Obes. 2019;12:2221-2236.

135. Mirabelli M, Chiefari E, Arcidiacono B, et al. Mediterranean diet nutrients to turn the tide against insulin resistance and related diseases. Nutrients. 12(4):1066.

136. Martucci M, Ostan R, Biondi F, et al. Mediterranean diet and inflammaging within the hormesis paradigm. Nutr Rev. 2017;75:442-455.

137. Darwiche G, Hoglund P, Roth B, et al. An Okinawan-based Nordic diet improves anthropometry, metabolic control, and health-related quality of life in Scandinavian patients with type 2 diabetes: a pilot trial. Food Nutr Res. 2016;60:32594.

138. Van Belle S, Affun-Adegbulu C, Soors W, et al. COVID-19 and informal settlements: an urgent call to rethink urban governance. Int J Equity Health. 2020;19:81.

139. Correa-Agudelo E, Mersha T, Hernandez A, Branscum AJ, MacKinnonNJ,CuadrosDF.Identification of VulnerablePopulations and Areas at Higher Risk of COVID-19 Related Mortality in the U.S. medRxiv. 2020. https://doi.org/10.1101/2020.07.11.20151563

140. Abedi V, Olulana O, Avula V, et al. Racial, Economic and Health Inequality and COVID-19 Infection in the United States. medRxiv. 2020. https://doi.org/10.1101/2020.04.26.20079756

141. Mode NA, Evans MK, Zonderman AB. Race, Neighborhood Economic Status, Income Inequality and Mortality. PLoS One. 2016;11:e0154535.

142. Abuelgasim E, Saw LJ, Shirke M, Zeinah M, Harky A. COVID-19: Unique public health issues facing Black, Asian and minority ethnic communities. Curr Probl Cardiol. 2020;45:100621.

143. Lassale C, Gaye B, Hamer M, Gale CR, Batty GD. Ethnic disparities in hospitalisation for COVID-19 in England: The role of socioeconomic factors, mental health, and inflammatory and pro-inflammatory factors in a community-based cohort study. Brain Behav Immun. 2020;88:44-49.

144. Raisi-Estabragh Z, McCracken C, Bethell MS, et al. Greater risk of severe COVID-19 in Black, Asian and Minority Ethnic populations is not explained by cardiometabolic, socioeconomic or behavioural factors, or by $25(\mathrm{OH})$-vitamin D status: study of 1326 cases from the UK Biobank. J Public Health (Oxf). 2020. https://doi. org/10.1093/pubmed/fdaa095

145. Rubin D, Huang J, Fisher BT, et al. Association of Social Distancing, Population Density, and Temperature With the Instantaneous Reproduction Number of SARS-CoV-2 in Counties Across the United States. JAMA Netw Open. 2020;3:e2016099.

146. SARS-CoV2 seroprevalence study in Mumbai: NTI Asayog-BMCTIFR study-First round report. Municipal Corporation of greater Mumbai, Public Realtion Department, 28-07-2020 2020. https:// www.livemint.com/news/india/mumbai-sero-prevalence-of-57found-in-slums-and-16-in-residential-societies-11595952896909. html. Accessed August 18, 2020.

147. Pereira RJ, Nascimento G, Gratao LHA, Pimenta RS. The risk of COVID-19 transmission in favelas and slums in Brazil. Public Health. 2020;183:42-43.

148. Smith RE. The effects of dietary supplements that overactivate the Nrf2/ARE System. Curr Med Chem. 2020;27:2077-2094.

149. Textor J, van der Zander B, Gilthorpe MS, Liskiewicz M, Ellison GT. Robust causal inference using directed acyclic graphs: the R package 'dagitty'. Int J Epidemiol. 2016;45:1887-1894. 
150. Haahtela T, von Hertzen L, Anto JM, et al. Helsinki by nature: The Nature Step to Respiratory Health. Clin Transl Allergy. 2019;9:57.

151. O'Callaghan C, Anto J. COVID-19: The Disease of the Anthropocene. Env Res. 2020;187:109683.

152. Vandana UK, Barlaskar NH, Gulzar ABM, et al. Linking gut microbiota with the human diseases. Bioinformation. 2020;16:196-208.

153. McCall LI, Callewaert C, Zhu Q, et al. Home chemical and microbial transitions across urbanization. Nat Microbiol. 2020;5:108-115.

154. Haahtela T, Anto J, Bousquet J. Fast and slow health crises of Homo urbanicus: loss of resilience in communicable diseases, like COVID-19, and non-communicable diseases. Porto Med J. 2020.5(4):e073. https://doi.org/10.1097/j.pbj.0000000000 000073

155. Haahtela T, Valovirta E, Bousquet J, Makela M. The Finnish Allergy Programme 2008-2018 works. Eur Resp J. 2017;49(6):2008-2018.

How to cite this article: Bousquet J, Anto JM, Czarlewski W, et al; ARIA group. Cabbage and fermented vegetables: From death rate heterogeneity in countries to candidates for mitigation strategies of severe COVID-19. Allergy. 2021;76:735-750. https://doi.org/10.1111/all.14549

\section{APPENDIX 1}

ARIA group: Amir Hamzah Abdul Latiff, Baharudin Abdullah, Werner Aberer, Nancy Abusada, Ian Adcock, Alejandro Afani, loanaAgache, XenofonAggelidis, Jenifer Agustin, Cezmi A. Akdis, Mübeccel Akdis, Mona Al-Ahmad, Abou Al-Zahab Bassam, Hussam Alburdan, Oscar Aldrey-Palacios, Emilio Alvarez Cuesta, Hiba Alwan Salman, Ashraf Alzaabi, Salma Amade, Gene Ambrocio, Rosana Angles, Isabella Annesi-Maesano, Ignacio J Ansotegui, JosepAnto, Paula Ara Bardajo, Stefania Arasi, Hasan Arshad, Maria Cristina Artesani, Estrella Asayag, Francesca Avolio, KhuzamaAzhari, Claus Bachert, Diego Bagnasco, Ilaria Baiardini, NisseraBajrović, Petros Bakakos, Sergio BakeyalaMongono, Christine Balotro-Torres, Sergio Barba, Cristina Barbara, Elsa Barbosa, Bruno Barreto, Joan Bartra, Eric D Bateman, LkhagvaaBattur, Anna Bedbrook, Martín Bedolla Barajas, Bianca Beghé, Antra Bekere, Elizabeth Bel, Ali Ben Kheder, Mikael Benson, Elena Camelia Berghea, Karl-Christian Bergmann, Roberto Bernardini, David Bernstein, Mike Bewick, Slawomir Bialek, Artur Białoszewski, Thomas Bieber, Nils E Billo, Maria Beatrice Bilo, Carsten Bindslev-Jensen, Leif Bjermer, Hubert Blain, Irina Bobolea, Malgorzata Bochenska Marciniak, Christine Bond, Attilio Boner, Matteo Bonini, Sergio Bonini, SinthiaBosnic-Anticevich, Isabelle Bosse, Sofia Botskariova, Jacques Bouchard, Louis-Philippe Boulet, Rodolphe Bourret, Philippe Bousquet, FulvioBraido, Andrew Briggs, Christopher E Brightling, Jan Brozek, Luisa Brussino, Roland Buhl, Roxana Bumbacea, Rosalva Buquicchio, María-Teresa Burguete Cabañas, Andrew Bush, William W Busse, Jeroen Buters, Fernan Caballero-Fonseca, Moïses A Calderon, Mario Calvo, Paulo Camargos, Thierry Camuzat, FR Canevari, Antonio Cano, G Walter Canonica, Arnaldo Capriles-Hulett, Luis Caraballo, Vicky Cardona, Kai-Hakon Carlsen, Jonas Carmon Pirez, Jorge Caro, Warner Carr,
Pedro Carreiro-Martins, Fredelita Carreon-Asuncion, Ana-Maria Carriazo, Thomas Casale, Mary-Ann Castor, Elizabeth Castro, A.G. Caviglia, Lorenzo Cecchi, Alfonso Cepeda Sarabia, Ramanathan Chandrasekharan, Yoon-Seok Chang, Victoria Chato-Andeza, LidaChatzi, Christina Chatzidaki, Niels H Chavannes, Claudia Chaves Loureiro, Marta Chelninska, Yuzhi Chen, Lei Cheng, Sharon Chinthrajah, Tomas Chivato, EkaterineChkhartishvili, George Christoff, Henry Chrystyn, Derek K Chu, Antonio Chua, Alexander Chuchalin, Kian Fan Chung, Alberto Cicerán, Cemal Cingi, Giorgio Ciprandi, levaCirule, Ana Carla Coelho, Enrico Compalati, Jannis Constantinidis, Jaime Correia de Sousa, Elisio Manuel Costa, David Costa, María del Carmen Costa Domínguez, André Coste, M. Cottini, Linda Cox, Carlos Crisci, Maria Angiola Crivellaro, Alvaro A Cruz, John Cullen, Adnan Custovic, Biljana Cvetkovski, Wienczyslawa Czarlewski, Gennaro D'Amato, Jane da Silva, Ronald Dahl, Sven-Erik Dahlen, Vasilis Daniilidis, Louei Darjazini Nahhas, Ulf Darsow, Janet Davies, Frédéric de Blay, Giulia De Feo, Eloisa De Guia, Chato de los Santos, Esteban De Manuel Keenoy, Govert De Vries, Diana Deleanu, Pascal Demoly, Judah Denburg, Philippe Devillier, Alain Didier, Sanja Dimic Janjic, Maria Dimou, Anh Tuan Dinh-Xuan, Ratko Djukanovic, Maria Do Ceu Texeira, Dejan Dokic, Margarita Gabriela Dominguez Silva, Habib Douagui, Nikolaos Douladiris, Maria Doulaptsi, Gérard Dray, Ruta Dubakiene, Eve Dupas, Stephen Durham, Marzia Duse, Mark Dykewicz, Didier Ebo, Natalija Edelbaher, Thomas Eiwegger, Patrik Eklund, Yehia ElGamal, Zeinab A. El-Sayed, Shereen S. El-Sayed, Magda El-Seify, Regina Emuzyte, Lourdes Enecilla, Marina Erhola, Heidilita Espinoza, Jesús Guillermo Espinoza Contreras, John Farrell, Lenora Fernandez, Antje Fink Wagner, Alessandro Fiocchi, Wytske J Fokkens, Lenia Folletti, Joao A Fonseca, Jean-François Fontaine, Francesco Forastiere, Jose Miguel Fuentes Pèrez, Emily GaerlanResureccion, Mina Gaga, José Luis Gálvez Romero, AmiranGamkrelidze, Alexis Garcia, Cecilia Yvonne García Cobas, María de la Luz Hortensia García Cruz, Jacques Gayraud, Matteo Gelardi, BilunGemicioglu, Dimitra Gennimata, Sonya Genova, José Gereda, Roy Gerth van Wijk, Antonio Giuliano, Maximiliano Gomez, Sandra González Diaz, Maia Gotua, Christos Grigoreas, InetaGrisle, Leo Gualteiro, Marta Guidacci, Nick Guldemond, Zdenek Gutter, Antonieta Guzmán, Tari Haahtela, RamsaHalloum, David Halpin, Eckard Hamelmann, Suleiman Hammadi, Richard Harvey, Enrico Heffler, Joachim Heinrich, Adnan Hejjaoui, BirtheHellquist-Dahl, Luiana Hernández Velázquez, Mark Hew, Elham Hossny, Peter Howarth, Martin Hrubiško, Yunuen Rocío Huerta Villalobos, Marc Humbert, Husain Salina, Michael Hyland, Guido laccarino, Moustafa Ibrahim, Nataliya Ilina, Maddalena Illario, Cristoforo Incorvaia, Antonio Infantino, Carla Irani, Zhanat Ispayeva, JuanCarlos Ivancevich, Edgardo EJ Jares, Deborah Jarvis, Ewa Jassem, KlemenJenko, Rubén Darío Jiméneracruz Uscanga, Sebastian L Johnston, Guy Joos, Maja Jošt, Kaja Julge, Ki-Suck Jung, Jocelyne Just, Marek Jutel, Igor Kaidashev, Omer Kalayci, FuatKalyoncu, Jeni Kapsali, PrzemyslawKardas, JussiKarjalainen, Carmela A. Kasala, Michael Katotomichelakis, Loreta Kavaliukaite, Bennoor S Kazi, Thomas Keil, Paul Keith, Musa Khaitov, Nikolai Khaltaev, 
You-Young Kim, Bruce Kirenga, JorgKleine-Tebbe, Ludger Klimek, Bernard Koffi N'Goran, EvangeliaKompoti, Peter Kopač, Gerard Koppelman, Anja KorenJeverica, Seppo Koskinen, MitjaKošnik, Kosta V. Kostov, Marek L Kowalski, Tanya Kralimarkova, Karmen Kramer Vrščaj, Helga Kraxner, SamoKreft, Vicky Kritikos, Dmitry Kudlay, Mikael Kuitunen, Inger Kull, Piotr Kuna, MaciejKupczyk, Violeta Kvedariene, MarialenaKyriakakou, Nika Lalek, Massimo Landi, Stephen Lane, DésireeLarenas-Linnemann, Susanne Lau, Daniel Laune, Jorge Lavrut, Lan Le, Martina Lenzenhuber, Marcus Lessa, Michael Levin, Jing Li, Philip Lieberman, Giuseppe Liotta, Brian Lipworth, Xuandao Liu, Rommel Lobo, Karin C Lodrup Carlsen, Carlo Lombardi, Renaud Louis, Stelios Loukidis, Olga Lourenço, Jorge A. Luna Pech, Bojan Madjar, Enrico Maggi, Antoine Magnan, Bassam Mahboub, AlpanaMair, Yassin Mais, Anke-Hilse Maitland van der Zee, Mika Makela, Michael Makris, Hans-Jorgen Malling, Mariana Mandajieva, Patrick Manning, Manolis Manousakis, Pavlos Maragoudakis, Gianluigi Marseglia, Gailen Marshall, Mohammad Reza Masjedi, Jorge F. Máspero, Juan José Matta Campos, Marcus Maurer, Sandra Mavale-Manuel, CemMeço, Erik Melén, Giovanni Melioli, Elisabete Melo-Gomes, Eli O Meltzer, Enrica Menditto, Andrew Menzies-Gow, Hans Merk, Jean-Pierre Michel, Yann Micheli, Neven Miculinic, Luís Midão, Florin Mihaltan, Nikolaos Mikos, Manlio Milanese, BranislavaMilenkovic, DimitriosMitsias, Bassem Moalla, Giuliana Moda, María Dolores Mogica Martínez, Yousser Mohammad, Mostafa Moin, Mathieu Molimard, Isabelle Momas, Monique Mommers, Alessandro Monaco, Steve Montefort, Dory Mora, Mario Morais-Almeida, Ralph Mösges, BadrEldin Mostafa, Joaquim Mullol, Lars Münter, Antonella Muraro, Ruth Murray, Antonio Musarra, TihomirMustakov, Robert Naclerio, Kari C. Nadeau, Rachel Nadif, AllaNakonechna, Leyla Namazova-Baranova, Gretchen Navarro-Locsin, Hugo Neffen, Kristof Nekam, Angelos Neou, Eustachio Nettis, Daniel Neuberger, Laurent Nicod, Stefania Nicola, Verena NiederbergerLeppin, Marek Niedoszytko, Antonio Nieto, Ettore Novellino, Elizabete Nunes, Dieudonné Nyembue, Robyn O'Hehir, Cvetanka Odjakova, Ken Ohta, Yoshitaka Okamoto, Kimi Okubo, Brian Oliver, Gabrielle L Onorato, Maria Pia Orru, Solange Ouédraogo, Kampadilemba Ouoba, Pier Luigi Paggiaro, Aris Pagkalos, Giovanni Pajno, Gianni Pala, SP Palaniappan, Isabella Pali-Schöll, Susanna Palkonen, Stephen Palmer, Carmen Panaitescu Bunu, Petr Panzner, Nikos G Papadopoulos, Vasilis Papanikolaou, Alberto Papi, BojidarParalchev, Giannis Paraskevopoulos, Hae-Sim Park, Giovanni Passalacqua, Vincenzo Patella, lan Pavord, Ruby Pawankar, Soren Pedersen, SusetePeleve, Simona Pellegino, Ana Pereira, Tamara Pérez, Andrea Perna, Diego Peroni, Oliver Pfaar, Nhân Pham-Thi, Bernard Pigearias, Isabelle Pin, Konstantina Piskou, ConstantinosPitsios, Davor Plavec, Dagmar Poethig, Wolfgang Pohl, AntonijaPoplasSusic, Todor A. Popov, Fabienne Portejoie, Paul Potter, Lars Poulsen, Alexandra Prados-Torres, FotisPrarros, David Price, Emmanuel Prokopakis, Francesca Puggioni, Elisa PuigDomenech, Robert Puy, Klaus Rabe, Filip Raciborski, Josephine
Ramos, Marysia T. Recto, Shereen M. Reda, Frederico S Regateiro, Norbert Reider, SietzeReitsma, Susana Repka-Ramirez, Erminia Ridolo, Janet Rimmer, Daniela Rivero Yeverino, José Angelo Rizzo, Carlos Robalo-Cordeiro, Graham Roberts, Nicolas Roche, Mónica Rodríguez González, Eréndira Rodríguez Zagal, Giovanni Rolla, Christine Rolland, Regina Roller-Wirnsberger, Miguel Roman Rodriguez, Antonino Romano, Jan Romantowski, Philippe Rombaux, Joel Romualdez, Jose Rosado-Pinto, Nelson Rosario, Lanny Rosenwasser, Oliviero Rossi, Menachem Rottem, Philip Rouadi, NikoletaRovina, Irma RozmanSinur, Mauricio Ruiz, Lucy Tania Ruiz Segura, Dermot Ryan, Hironori Sagara, Daiki Sakai, Daiju Sakurai, Wafaa Saleh, Johanna Salimaki, Konstantinos Samitas, BoleslawSamolinski, María Guadalupe Sánchez Coronel, Mario Sanchez-Borges, Jaime Sanchez-Lopez, CodrutSarafoleanu, Faradiba Sarquis Serpa, Joaquin Sastre-Dominguez, Eleonora Savi, BisherSawaf, Glenis K Scadding, Sophie Scheire, Peter SchmidGrendelmeier, Juan Francisco Schuhl, Holger Schunemann, Maria Schvalbová, Jorgen Schwarze, Nicola Scichilone, Gianenrico Senna, Cecilia Sepúlveda, Elie Serrano, Aziz Sheikh, Mike Shields, Vasil Shishkov, Nikos Siafakas, Alexander Simeonov, Estelle FER Simons, Juan Carlos Sisul, BrigitaSitkauskiene, IngelbjorgSkrindo, Tanja SokličKošak, Dirceu Solé, Talant Sooronbaev, Manuel SotoMartinez, Manuel Soto-Quiros, Barnaro Sousa Pinto, Milan Sova, Michael Soyka, Krzysztof Specjalski, Otto Spranger, Sofia Stamataki, Lina Stefanaki, Cristiana Stellato, Rafael Stelmach, Timo Strandberg, Petra Stute, Abirami Subramaniam, Charlotte Suppli Ulrik, Michael Sutherland, Silvia Sylvestre, AikateriniSyrigou, Luis Taborda Barata, NadejdaTakovska, Rachel Tan, Frances Tan, Vincent Tan, Ing Ping Tang, Masami Taniguchi, Line Tannert, PongsakornTantilipikorn, Jessica Tattersall, Filippo Tesi, Carel Thijs, Mike Thomas, Teresa To, Ana Maria Todo-Bom, Alkis Togias, PeterValentin Tomazic, Vesna Tomic-Spiric, Sanna Toppila-Salmi, Elina Toskala, Massimo Triggiani, Nadja Triller, Katja Triller, Ioanna Tsiligianni, M. Uberti, Ruxandra Ulmeanu, Jure Urbancic, Marilyn Urrutia Pereira, Martina Vachova, Felipe Valdés, Rudolf Valenta, Marylin Valentin Rostan, Antonio Valero, Arunas Valiulis, Mina Vallianatou, Erkka Valovirta, Michiel Van Eerd, Eric Van Ganse, Marianne van Hage, Olivier Vandenplas, Tuula Vasankari, Dafina Vassileva, Cesar Velasco Munoz, Maria Teresa Ventura, Cécilia Vera-Munoz, DilyanaVicheva, Pakit Vichyanond, Petra Vidgren, Giovanni Viegi, Claus Vogelmeier, Leena Von Hertzen, Theodoros Vontetsianos, Dimitris Vourdas, Vu Tran Thien Quan, Martin Wagenmann, Samantha Walker, Dana Wallace, De Yun Wang, Susan Waserman, Magnus Wickman, Sian Williams, Dennis Williams, Nicola Wilson, Gary Wong, Kent Woo, John Wright, Piotr Wroczynski, Paraskevi Xepapadaki, Plamen Yakovliev, Masao Yamaguchi, Kwok Yan, Yoke Yeow Yap, Barbara Yawn, Panayiotis Yiallouros, Arzu Yorgancioglu, Shigemi Yoshihara, Ian Young, Osman B Yusuf, Asghar Zaidi, Fares Zaitoun, Heather Zar, M.T. Zedda, Mario E Zernotti, Luo Zhang, Nanshan Zhong, Mihaela Zidarn, Torsten Zuberbier, Celia Zubrinich. 